\title{
Mapping epileptic activity: sources or networks for the clinicians?
}

\author{
Francesca Pittau ${ }^{1}$, Pierre Mégevand ${ }^{2}$, Laurent Sheybani ${ }^{3}$, Eugenio Abela ${ }^{4}$, Frédéric Grouiller ${ }^{5}$, \\ Laurent Spinelli ${ }^{1}$, Christoph M. Michel ${ }^{3}$, Margitta Seeck $^{1}$ and Serge Vulliemoz ${ }^{1}$ * \\ 1 EEG and Epilepsy Unit, Neurology Department, University Hospitals and Faculty of Medicine of Geneva, Geneva, Switzerland \\ 2 Laboratory for Multimodal Human Brain Mapping, Hofstra North Shore LIJ School of Medicine, Manhasset, NY, USA \\ ${ }^{3}$ Functional Brain Mapping Laboratory, Department of Fundamental Neurosciences, University of Geneva, Geneva, Switzerland \\ ${ }^{4}$ Support Center of Advanced Neuroimaging (SCAN), Institute for Diagnostic and Interventional Neuroradiology, University Hospital Inselspital, Bern, Switzerland \\ ${ }^{5}$ Radiology Department, University Hospitals and Faculty of Medicine of Geneva, Geneva, Switzerland
}

\section{Edited by:}

Patrick William Carney, The Florey

Institute of Neuroscience and Mental

Health, Australia

\section{Reviewed by:}

Mario Alonso, Instituto Nacional de Neurología y Neurocirugía, Mexico

Christine T. Ekdahl, Lund University, Sweden

*Correspondence:

Serge Vulliemoz, EEG and Epilepsy

Unit, Neurology Department,

University Hospitals of Geneva, 4 rue

Gabrielle-Perret-Gentil, Geneva 4

1211, Switzerland

e-mail: serge.vulliemoz@hcuge.ch
Epileptic seizures of focal origin are classically considered to arise from a focal epileptogenic zone and then spread to other brain regions. This is a key concept for semiological electroclinical correlations, localization of relevant structural lesions, and selection of patients for epilepsy surgery. Recent development in neuro-imaging and electro-physiology and combinations, thereof, have been validated as contributory tools for focus localization. In parallel, these techniques have revealed that widespread networks of brain regions, rather than a single epileptogenic region, are implicated in focal epileptic activity. Sophisticated multimodal imaging and analysis strategies of brain connectivity patterns have been developed to characterize the spatio-temporal relationships within these networks by combining the strength of both techniques to optimize spatial and temporal resolution with whole-brain coverage and directional connectivity. In this paper, we review the potential clinical contribution of these functional mapping techniques as well as invasive electrophysiology in human beings and animal models for characterizing network connectivity.

\section{INTRODUCTION}

Epilepsy is one of the most frequent chronic neurological disorder, with an incidence of 50/100,000/year and a prevalence of $0.5-1 \%(1,2)$. One third of these patients are drug resistant $(3)$. Focal seizures are classically considered to be caused by an abnormal neuro-electrical activity of a focal epileptogenic zone and a subsequent spreading to other brain regions. This concept is intimately linked to the correlation between ictal signs and symptoms, electro-physiological activity, and structural lesion [anatomoelectro-clinical correlation (4)]. Furthermore, this hypothesis is crucial to select drug-resistant focal epilepsy patients for surgery, a widely accepted effective therapy $(5,6)$. The aim of epilepsy surgery is to remove the epileptogenic zone with the preservation of the eloquent areas (7).

Recent progress in neuro-imaging and electro-physiology suggests that focal seizures and focal epilepsies are actually related to an abnormal function of a network of cortical and subcortical brain structures rather than to a single epileptogenic region (8-14). The occurrence of epileptic activity is due to the abnormal neuronal activity of these connected regions and abnormal interactions between them (epileptic network). This conceptual shift is reflected in the new terminology proposal for seizures and epilepsies of the International League against Epilepsy, which proposes "focal" as indicating seizures arising primarily "within networks limited to one hemisphere and that may be discrete or more widely distributed" (15). Generalized seizures are considered as "originating within and rapidly engaging, bilaterally distributed networks" of cortical and subcortical regions. Inside these networks, some brain regions are responsible for seizure initiation and propagation, whereas other nodes are more remotely involved, their activity modulating, or being modulated by the epileptic discharge.

There is increasing evidence that epileptic activity strongly interacts with physiological brain networks, notably the so-called "resting-state networks" (RSNs) $(8,16)$. A RSN is a set of brain regions that shows temporal correlations in their activity (as measured by hemodynamic or electrical signals) and that are functionally related. They are observed during rest but correspond to the networks revealed in different behavioral and cognitive task (e.g., attention, vision, etc.). This has led to the new concept that the apparently resting spontaneous brain activity shows continuous interaction among brain networks responsible for various classes of sensory/behavioral functions (17). RSNs are highly organized in space, reproducible from subject to subject, and differ with aging and between genders (18).

In this paper, we review the converging evidence from different brain mapping techniques in human and animal models that epilepsy is related to the dysfunction of a large-scale brain networks, with alterations of physiological brain networks. We will particularly focus on the clinical impact of this new view of epilepsy as a network disease.

\section{METHODS}

An electronic literature search was conducted for articles on this topic regarding human and animal subjects. Sources searched included PubMed and relevant books. Words used in the search 
included the text words and subject headings of epilep ${ }^{\star}$, functional connect $^{*}$, resting-state functional network ${ }^{\star}$, temporal epilepsy, extra-temporal epilepsy, electroencephalogram (or EEG), simultaneous functional MRI (fMRI) and EEG (or EEG-fMRI), electric and magnetic source imaging (or MSI, ESI), intracranial EEG (or iEEG or sEEG), cortico-cortical evoked potential, and single-pulse electrical stimulation. The words were searched independently and in combination. For each citation considered, the abstract was read (when available), and articles were excluded if they were outside the scope of the review. Studies published only in abstract form, letters, and technical reports were excluded. The bibliography of each of the retrieved papers was examined to identify relevant references that could have been missed by electronic search. The findings were described taking into account the limit of words and the critical insight of the authors.

\section{HOW TO MEASURE RESTING-STATE NETWORKS? FUNCTIONAL CONNECTIVITY}

Functional interactions between brain regions activity, can be characterized in several ways. On the one hand, functional connectivity (FC), the most widely used metrics, measures the statistical dependency between different signals obtained by correlation analysis. However, such strategy does not account for the direction of the information flow and cannot therefore infer causality relationships. On the other hand, effective or directed connectivity investigates directional relationships and aims at describing causal influences. Effective connectivity can be investigated using model-driven techniques such as structural equation modeling (19) and dynamic causal modeling (DCM) (20), data-driven techniques such as Granger-causal modeling (21), or by recording the response of remote areas to focal stimulation of a given brain region [cortico-cortical evoked potentials (22)]. Connectivity studies can be applied among a set of predefined relevant brain regions selected by the investigator, between one seed region and the rest of the brain or at the whole-brain scale, using the spatial resolution of the recording technique. A detailed description of the various approaches used for measuring connectivity is beyond the scope of this review and the reader is referred to studies comparing various approaches to better understand the specific limitations of each technique (23-25). The results obtained by such connectivity analysis between all pairs of brain regions can be represented in so-called connectivity matrices. Graph topological analysis is then increasingly applied to reduce the complexity of the data and extract meaningful characteristics of the networks (26).

\section{BLOOD OXYGEN LEVEL DEPENDENT SIGNAL AND PHYSIOLOGICAL RESTING-STATE NETWORKS}

The concept of brain networks originated, and has largely benefited, from the use of resting-state fMRI. fMRI detects blood oxygen level dependent (BOLD) signal change reflecting metabolically active brain areas not only in relation to a specific physiologic or pathologic event (27) but also in resting-state (RS) condition (resting-state-fMRI or RS-fMRI).

Biswal and colleagues demonstrated for the first time (1995) that brain regions that are functionally related, show temporal correlations in the low frequency component of the BOLD signal. In other words, fMRI FC detects zones that exhibit correlated BOLD fluctuations and, as a result, belong to the same functional network (28). Studies in monkeys (29) and in human beings (30) suggest that FC is related to neuronal processes.

Functional connectivity can be measured while the subject is performing a behavioral and cognitive task (task-related FC), or while the subject is not performing any specific task (RS-FC). The RSN that is mainly activated in condition of resting wakefulness and deactivated in task performing is called default-mode network (DMN) (31). This physiological RSN is involved in selfreferential thoughts and consciousness $(32,33)$. The concept of "resting" is debatable. Usually, subjects are instructed to lie down in the scanner with the eyes closed, and are invited to not sleep.

Different methods have been developed to extract RSNs, some requiring an "a priori hypothesis," like seed-based approach (34), other do not [i.e., independent component analysis (35), or bootstrap analysis (36)]. The description of the methodological aspects is outside the scope of this review. Other papers can be consulted $(14,37,38)$.

\section{EEG/MEG AND PHYSIOLOGICAL RESTING-STATE NETWORKS}

Functional connectivity algorithms similar to those used for fMRI BOLD signals can be applied to MEG or EEG current-density estimations in the source space, revealing brain areas that are synchronized in specific frequency bands. As with fMRI, such analysis can be applied to task-related (39), as well as to spontaneous resting-state activity $(40,41)$. The unique advantage of EEG/MEG connectivity analysis is the high temporal resolution that allows studying fast fluctuations within large-scale network interactions and fast switches between resting-state networks.

FC analysis of EEG/MEG considers the time-course of electromagnetic signals and looks at correlations of oscillating networks (42). Beyond this view of temporal oscillations, EEG recordings can be considered as time-series of scalp potential maps that vary across time with the temporal resolution in the order of milliseconds (43). Several studies have shown that spontaneous EEG signals can be explained by the alternation of periods of stable topography, lasting almost $100 \mathrm{~ms}$, very reproducible across subjects, and modifiable by neurological (44) or psychiatric impairment (45). These periods are called microstates and can be identified throughout an individual's life (46) suggesting that they might be mediated by predetermined anatomical connections. During rest, four different microstates are consistently observed, and they can be considered as "basic building blocks" of spontaneous mental activities (47). A recent review on this topic is available (48).

It has been shown (49) that the temporal dynamic of EEG microstates have hemodynamic correlates that can be measured with EEG-fMRI and that each physiological microstate map corresponds to one of the well-described BOLD RS network. Such clear correlates between EEG and BOLD are less well found when looking at classical power fluctuations in specific EEG frequency bands (50). This finding strongly suggests that the EEG microstates can be the candidates for the electro-physiological signatures of fMRI RSNs. Scale-invariance of the alternation between microstates has been demonstrated to be the base of this coupling over such a wide temporal scale (51). 


\section{EVIDENCE FOR BRAIN NETWORKS INVOLVED IN EPILEPTIC ACTIVITY}

As described above, FC at the whole-brain level can be studied with EEG, MEG, fMRI, iEEG, or the combination of these techniques. They have been applied to patients with focal or generalized epilepsy to characterize spatial and temporal properties of epileptic networks.

\section{EEG AND MEG-BASED CONNECTIVITY IN EPILEPSY}

EEG and MEG are appealing non-invasive techniques for estimating brain connectivity in epilepsy because they measure neuroelectrical activity more directly than fMRI and can potentially offer a higher temporal resolution.

Several studies using concordance with intracranial recordings or post-operative outcome have established that electric and magnetic source imaging (ESI, MSI) are reliable techniques for estimating the localization of the cortical generators of epileptic activity (52-55) and these techniques now offer a much more convincing strategy to investigate connectivity directly between the activity of cortical regions. Therefore, both ESI and MSI studies will be discussed together hereunder. Studies using connectivity analysis in the sensor space are not discussed here because of their severe limitations of interpretation due to important caveats related to sensor cross-talk, volume conduction, and reference choice of the electromagnetic signals (56). The projection of the signal in source space requires the selection of a head model describing the propagation of the electromagnetic signal (forward problem) and an inverse solution (estimating the cortical activity from the EEG/MEG recording, inverse problem) $(48,57,58)$. A variety of head models exists, from template averaged normal brain to highly sophisticated realistic models based on individual anatomy, and they have been used in epilepsy imaging and cognitive neurosciences. Validation in patients with invasive EEG or surgical resection showed that the individual anatomy was important for the localization accuracy (54), but that the performance of highly sophisticated models did not outperform less computerintensive models also based on individual anatomy, as these were disturbed by the presence of brain lesions in patients with epilepsy (59). Regarding inverse solutions, dipole models consider a single or a few equivalent dipole(s) as sources of the EEG/MEG signals of sources distributed in the whole cortex (48). While both approaches might yield complimentary results for localizing epileptic sources (60), distributed sources are best suited to the study of connectivity between cortical patches at a large brain scale.

The analysis of interictal epileptic discharges has principally aimed at localizing epileptic generators in the context of presurgical evaluations rather than studying large brain networks. Case reports or small MEG series showed promising results for the localizing value of the regions with high information outflow, estimated by connectivity analysis (61-63). In addition, based on development in cognitive neurosciences, the background activity measured by MEG and EEG in the classical frequency bands has also been used as a substrate to estimate abnormal connectivity in patients with epilepsy and correlate it with clinical variables. In patients with brain tumors, increased theta-band connectivity and more profound network alterations were associated with a higher number of epileptic seizures (64) and there is higher post-operative network improvement in patients who become seizure free (65).

In generalized epilepsies, connectivity studies have highlighted a network of hyperconnected anterior regions in photosensitive patients (66). Network analysis using graph theory in five patients with absence epilepsy showed a build-up of connectivity changes occurring before the onset of generalized spike-wave discharges (67). This shows the potential of such a technique for our understanding of the large-scale brain networks underlying hyperexcitability and interictal to ictal transition. A similar approach has been applied to iEEG recordings of interictal to ictal transition in patients with focal cortical dysplasia (12).

Another study used co-occurrence of MEG interictal spikes to build graphs of connectivity between the estimated sources of these spikes. In seven patients also investigated with stereotactic iEEG, the connections revealed by MEG were confirmed by iEEG (68).

Similarly to fMRI studies, future work will need to distinguish between transient connectivity alterations related to interictal discharges, that are known to be associated with subtle cognitive impairment (69), and deeper connectivity changes based on background activity alterations. The tools are now available to benefit from the high temporal resolution of EEG/MEG to further investigate these issues and this field has recently attracted an intense interest. While MEG offers advantages over EEG for longitudinal studies of post-operative cases, due to its insensitivity to skull defects, the development of long-term high-density EEG system, its greater versatility compared to MEG and its potential combination with fMRI will be precious for recording seizures and exploring network changes leading to their initiation, spread, and termination.

\section{EEG-fMRI CONNECTIVITY IN EPILEPSY}

Simultaneous EEG and fMRI (EEG-fMRI) detects hemodynamic changes in the brain related to events of interest identified in the EEG (70). Combining high temporal resolution of EEG signal with high spatial resolution of BOLD images, EEG-fMRI has been shown to be useful to characterize various forms of focal and generalized epileptic abnormalities (hereunder called "spikes" for practical reasons) (71). EEG-fMRI helps to localize epileptic focus in patients with drug-resistant focal epilepsy candidate for surgery $(72,73)$. From the first publications $(74,75)$, EEG-fMRI has demonstrated that BOLD responses to a focal spike can be multifocal, also present at a distance from the presumed focus (Figure 1), corroborating the concept of epileptic network (9). Studying such networks can inform about patients' prognosis after surgery. While focal responses predict a good post-operative outcome, diffuse results are associated with a poor outcome, probably reflecting that a larger network is involved in the epileptogenic zone $(76,77)$. Epileptic activity can also be detected in the absence of spikes and fMRI analysis based on EEG topography can reveal epileptogenic networks (78).

BOLD responses to a neural event are usually detected with a delay of 4-6s (79). Nevertheless, hemodynamic changes to spikes can have different peak times (80), and can occur before the spike is visible on the scalp (81). Dynamic analysis of BOLD response $(82,83)$ can tell us which brain areas are first activated, 


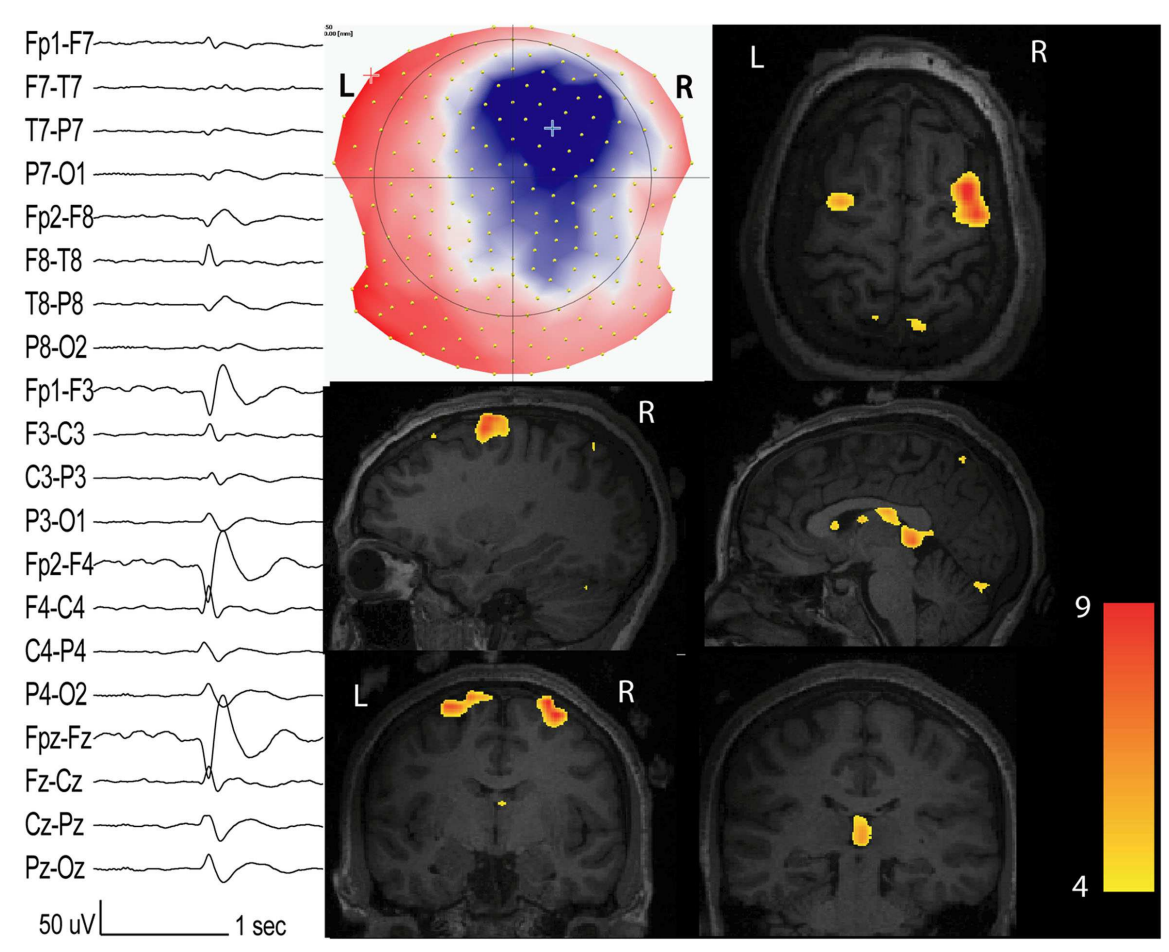

FIGURE 1 | Interictal network revealed by EEG-fMRI. Patients with non-lesional right frontal epilepsy. Marked events inside the EEG-fMR session: right frontal spikes with phase reversal at F4 (on the left: longitudinal bipolar montage from 204 channels EEG). On the middle: scalp voltage map of the spike (204 electrodes, viewed from the top) with the maximal right frontal negativity (blue). BOLD response ( $t$-value $=4 ; p<0.05$ corrected for family-wise-error) has maximal activation in the spike topography but other clusters with inferior statistical values are present in the contra-lateral homologous region and in the thalamus. by comparing early BOLD response vs. late BOLD response. However, this analysis does not address the concept of causality and the sluggishness and variability of BOLD responses prevent a more accurate investigation into the temporal dynamics and directionality of the connections (24). Causality within epileptic network can be addressed by effective connectivity approaches like Dynamic Causal Modeling (DCM) $(37,84)$.

The combination of ESI with EEG-fMRI can offer complementary information for improving each single technique (Figure 2). Although EEG-fMRI and ESI measure different signals (hemodynamic the first, electrical the second), the concordance between ESI performed during fMRI recordings can allow distinguishing between hemodynamic changes related to spike onset vs. propagation, adding important temporal information to the limited fMRI temporal resolution $(85,86)$.

EEG-fMRI studies can give insights about epileptogenesis. Interictal spikes of different types of epilepsy (frontal, temporal, and posterior quadrant), are associated with deactivation in the precuneus and posterior cingulate cortex (10), regions involved in the DMN (Figure 3). Other physiological RSNs could be affected by spikes: this interaction and its clinical consequences need to be clarified in future studies. A common involvement of the cingulate gyri in temporal lobe and frontal lobe epilepsy was reported (10), probably resulting from rapid spread of epileptic activity originating from the temporal and frontal areas, which both involve the limbic system.
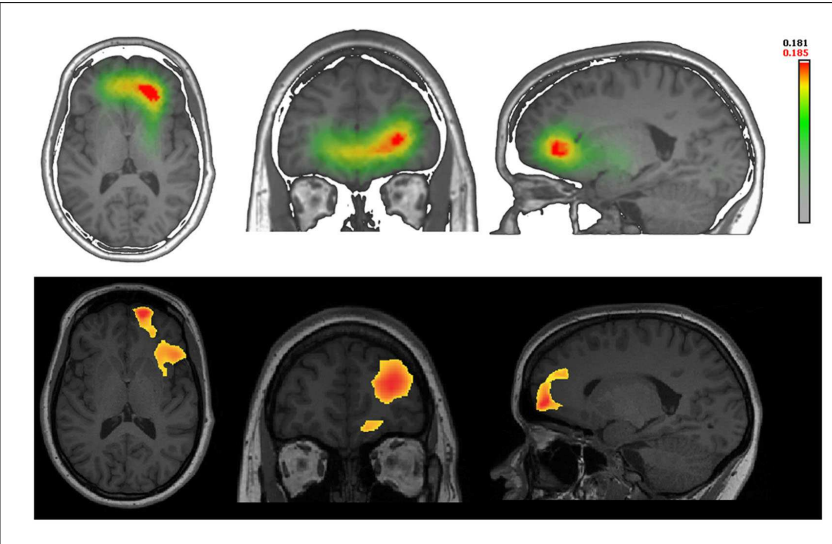

$3.1 \square .5$

FIGURE 2 | Techniques using different types of signal are concordant in localizing the epileptic focus in a patient with right orbito-frontal focal cortical dysplasia. On the top-line: ESI (256 electrodes, simplified realistic head model ISMAC, distributed inverse solution LORETA) performed on right frontal spikes (FP2-F8). On the bottom-line: EEG-fMRI performed on the same type of events recorded inside the scanner.

A specific area, localized in the medial orbito-frontal gyrus (piriform cortex), called "area tempestas", seems to be involved in the genesis or propagation of epileptic activity $(87,88)$ in focal 


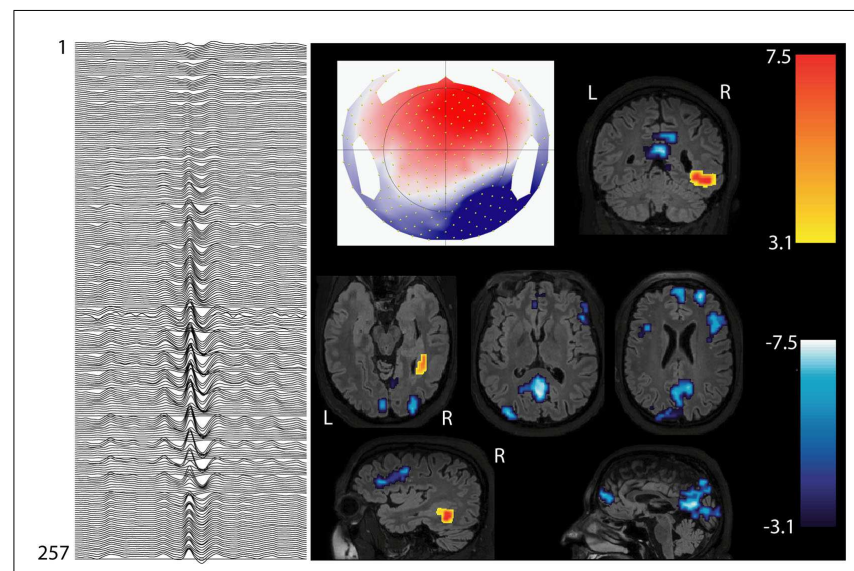

FIGURE 3 | Interictal involvement of DMN in focal epilepsy. Patients with right hemispheric extended periventricular nodular heterotopia. Marked epileptic events inside the scanner: right posterior temporal spikes with phase reversal at P8 (on the left: 256 channel EEG; referential montage $\mathrm{Fz}-\mathrm{Cz}$ ). BOLD increase is concordant with the spike topography (topographic map on the middle), whereas BOLD decrease is present in the regions of default-mode network (DMN)

epilepsies. A DCM study supported the hypothesis of a causal link between hemodynamic changes in this structure and a specific type of reflex epilepsy, although in a single patient (89). Several other findings seem to corroborate the important role of the area tempestas: (i) its decrease in benzodiazepine receptor (87), (ii) its epileptogenic role in animal kindling models of temporal lobe epilepsy (TLE) (90-92), and (iii) its increase in gray matter volume in patient with frontal lobe epilepsy when compared to controls (93).

From a methodological point of view, multimodal combination between EEG/ESI, fMRI, and diffusion imaging tractography will allow exploring functional and structural connectivity at a finer spatio-temporal scale. Some initial small studies have highlighted the potential of these combinations (94-96).

\section{fMRI and EEG-fMRI studies in focal epilepsy}

Unfortunately, only few of the many studies on RS-FC have been done with the simultaneous recording of EEG. Spikes cause a transient cognitive impairment, by affecting, e.g., memory retrieval in rats (97), and memory maintenance and retrieval in human beings (69). Therefore, a more consistent use of simultaneous EEG while performing $\mathrm{AMRI}$ for RS or task-related studies in epileptic patients is needed to determine the influence of spikes on the determined BOLD networks. Indeed a study where EEG activity was monitored during a working memory-fMRI session (98) has shown that the task-related BOLD dramatically changes when spikes occur. Another advantage of the simultaneous recording of EEG in the scanner is that it allows monitoring the transition between different alertness states in order to assure that the subject is in RS and not in drowsiness/sleep state. A very recent review (99) has accurately discussed this issue and summarized the relevant studies.

Temporal lobe epilepsy. The majority of RS-fMRI studies in focal epilepsies have focused on TLE, which is the most common form of focal epilepsy in adults and offers the advantage of being one of the most homogeneous groups within the focal epilepsy syndromes.

Temporal lobe epilepsy has been the first epileptic syndrome to be considered as epileptogenic network (100) with relatively well characterized components encompassing different structures in the mesial temporal lobe (amygdala and hippocampus), adjacent cortex including enthorhinal cortex and lateral temporal cortex, and extra-temporal structures (i.e., thalamus and orbito-frontal cortex). fMRI connectivity studies (some with simultaneous EEG recording, others without) conducted by seeding the principal nodes of the mesial temporal network showed impaired connectivity with the other nodes of the network (101-103). Decreased connectivity is the most common finding among those studies. Nevertheless, there are reports of increased function of the unaffected hippocampus in patients with unilateral MTLE, both in the RS (104) and during task-related $(105,106)$ acquisitions. Morgan et al. (107) have shown that RS cross-hippocampal FC is disrupted at the beginning of the disease and then increases linearly with epilepsy duration after 10 years, suggesting that length of disease influences FC patterns. Bettus et al. (108) studied the electro-physiological correlates of BOLD signal fluctuations in structures exhibiting epileptiform discharges, by measuring correlations between intracerebral EEG and resting-state fMRI in five patients with TLE. They found an increase in connectivity measured from the intracerebral EEG but a decrease of connectivity measured from the BOLD signal in regions with epileptiform abnormalities relative to non-affected areas. This discrepancy, obtained by measuring connectivity of two signals of different nature (electrical and hemodynamic), demonstrates the challenge in interpreting connectivity changes. It could also suggest an alteration of neurovascular coupling in TLE.

In unilateral mesial TLE (MTLE), the affected amygdala and hippocampus (and to a lesser extent on the contra-lateral side) are less connected between them and also with other consistent RSNs, such as the mesolimbic and the DMN, suggesting that these functional interictal changes explain cognitive and psychiatric impairments often found in patients with this type of epilepsy (109). Several fMRI studies, with and without EEG, have shown an abnormal FC between physiological consistent RSNs [i.e., language (110)] and MTL structures.

Default-mode network. Laufs and colleagues (8) have shown that deactivation in DMN, involved in consciousness, is more frequent for spikes in patients with TLE than extra-TLE. Deactivation in the same regions in response to temporal spikes was also demonstrated by Kobayashi et al. (111) and by Fahoum et al. (10). Frings et al. (112) showed decreased DMN-hippocampus FC in MTLE patients compared to controls during an object-location memory task, underlying the importance of the intact connection between these structures to preserve memory. This concept was validated in post-surgical follow-up studies (see below). An impairment of the connections between DMN and MTL structures has been demonstrated also in RS with a seed-based fMRI analysis (113). The same group (114) combined fMRI RS-FC and diffusion tensor imaging, and showed that the decreased FC within the DMN in MTLE is correlated to abnormal structural connectivity. Although functional DMN connectivity is generally decreased in MTLE, few nodes can 
be hyperconnected and this may play a compensatory role for the loss of functional connections in other regions of the network (115). The same study, performed with an independent component analysis, has also shown distinct patterns of FC impairment with DMN between the left and right MTLE. The same difference has been further reported (116), suggesting that impaired cognition and memory in TLE may be different in right vs. left TLE. Morgan and colleagues (117) have identified a region in the ventral lateral nucleus of the right thalamus whose connectivity to the hippocampi separates left from right TLE subjects, suggesting that quantifying resting-state FC across this network may be a potential indicator of lateralization of TLE (useful step in the pre-surgical assessments).

Functional connectivity findings are related with clinical data: McCormick et al. (118) shows that MTLE patients with respect to controls have reduced connectivity from the posterior DMN to the epileptogenic hippocampus and increased DMN connectivity to the contra-lateral hippocampus. Stronger DMN connectivity to the epileptogenic hippocampus was associated with better presurgical memory and with greater postsurgical memory decline, whereas stronger DMN connectivity to the contra-lateral hippocampus was associated with less postsurgical memory decline. Following surgery, DMN connectivity to the remaining hippocampus increased from pre-surgical values and showed enhanced correlation with postsurgical memory function.

Hippocampi are considered by some authors as nodes of the DMN (119), but there is not unanimity on this interpretation (32, $120,121)$. It is important to remember that all the regions of the brain can be functionally connected: a region belonging to a specific network (like the mesial temporal network) can belong also to a less specific network encompassing the previous one. This classification depends on how many different physiological RSNs are extracted from specific analyses: for instance, by extracting four physiological RSNs, the probability that the mesial temporal regions will be included in the DMN is higher than if the number of extracted network is higher (122).

Mesolimbic network. Patients with unilateral MTLE have important decreases of FC with the ventromesial limbic prefrontal regions and with the nucleus accumbens (109). These regions belong to a dopaminergic mesolimbic network, involved in longterm memory for novel events and reward (123). Hippocampus and amygdala have been often described as part of this network $(124,125)$, and several findings suggest that this network is affected in MTLE. The preferential seizure spread from mesial temporal lobes to mesial frontal lobes, especially the orbito-frontal cortex, has been demonstrated by ictal iEEG in patients with MTLE, suggesting that mesial orbito-frontal cortex is strongly affected by mesial temporal activity (126). On the other hand, dopaminergic alterations have been demonstrated in the pathophysiology of major depression, and dysfunctional activity of the mesolimbic dopaminergic system plays a crucial role in depressive behavior $(127,128)$. Structures belonging to mesolimbic network are functionally (129) and structurally (130) impaired in MTLE patients who have psychiatric impairments, such as anxiety/depression. A recent study (131) showed that the subgenual anterior cingulate cortex (mesolimbic network key-node) is affected only in MTLE patients that have primary affective disorders and not in those without such disorders and neither in controls. The same study confirms these FC findings with voxelbased morphometry and diffusion tensor imaging, corroborating the concept that the affective psychopathology often diagnosed in patients with MTLE has a neurobiological correlate. Antidepressant drugs, when effective, could modulate these connectivity impairments.

The amygdala has often been described as part of mesolimbic network and it is also involved in emotional processing of stimuli. Facial emotion recognition, particularly for "fear," is impaired in patients with TLE, especially on the right hemisphere (132-135). Broicher and colleagues (136) showed through fearful-face fMRIparadigm that the altered amygdala FC in TLE patients is strongly related to the poor performance in behavioral tests evaluating the theory of mind abilities (ability of decoding thoughts and behavior of other human beings). Another study with the same paradigm showed that, in right TLE patients, pre-operative right amygdala activation correlates with post-operative change of anxiety and depression scores [i.e., greater increases in anxiety and depression in patients with greater preoperative activation (137)]. This confirms that pre-surgical study of FC between TLE and other brain structures can help to predict post-surgery neuropsychological consequences.

Attention network. Several studies have shown that dorsal and ventral attention networks are functionally altered in MTLE, explaining why patients with this type of epilepsy have often worse performances than healthy controls (HC) in attention tasks. Cataldi et al. (138) have recently reviewed this topic.

Extra-temporal lobe epilepsy. Extra-temporal lobe epilepsies are characterized by a wide range of focus localization and etiology. For this reason, group studies with homogeneous clinical phenotype are difficult to achieve. This contrasts with the large body of group studies in MTLE, which take advantage from the frequent uniform pathology of atrophy and cell-loss in amygdala-hippocampus structures. A group-analysis EEG-fMRI study in different types of epilepsy (frontal, temporal, and posterior quadrant) showed that focal spikes are associated with networks of widespread metabolic changes, specific for each type of epilepsy (10).

Negishi et al. (139) revealed higher lateral pre-surgery FC maps in drug-resistant patients with good surgical outcome (seizure-free at 1-year) compared to those with poor outcome. A recent study on 23 patients with frontal lobe epilepsy used the same seed-FC approach (seed at maximal BOLD value of the spike-related activation map) (140), finding an increased FC in the neighborhood of the seed and a decrease in regions remote to the seed compared to controls. Patient-specific connectivity pattern was not significantly changed when comparing fMRI runs with spikes vs. fMRI without any spike detectable on the simultaneous EEG. Patients with drugresistant frontal lobe epilepsy (141) recruit wider areas compared to controls when performing an fMRI memory encoding task paradigm, particularly in the contra-lateral frontal lobe, suggesting the presence of compensatory mechanisms to maintain memory function. 


\section{Generalized epilepsy}

Different theories have been proposed about the patho-physiology of "generalized seizures". Meeren et al. (142) reviewed this topic. All these theories consider cortex and thalamus as being involved in the generation of the typical $2.5-4 \mathrm{~Hz}$ generalized spike-wave discharges (GSWD) detected on scalp EEG, but it is still unclear, which of them is the "primum movens" (143). As discussed below, animal studies in genetic models of absence epilepsy are crucial to gain understanding of these conditions because no invasive validation can be contemplated in human beings. These animal studies suggest that GSWDs are triggered in a restricted cortical region (144-147).

Several EEG-fMRI studies showed that during short GSWD (16, 148-150) and absence (151-154), there is a characteristic pattern of subcortical (medio-dorsal thalamic and striatus) activation and cortical deactivation, especially in areas of the DMN. It has been hypothesized that the DMN deactivation is linked to reduced consciousness (i.e., absences) $(16,155,156)$. A dynamic analysis study on 17 absences from nine patients with absence epilepsy and classical pattern of 3-4 Hz GSWDs (83) showed that BOLD responses were remarkably consistent in space and time across different absences of one patient, but were different from patient to patient. Furthermore, this study shows early frontal BOLD activations (specific for each patient), supporting the cortical focus theory. Another EEG-fMRI study on 11 children with absence seizures (157) revealed that the first brain zone showing BOLD increase was the parietal cortex, this activity starting $10 \mathrm{~s}$ before the onset of the discharge. Additionally, this study demonstrated the hemodynamic involvement of subcortical structures in GSWD, including the reticular structures of the brainstem. Focal cortical involvement before the onset of GSWD has been demonstrated also by a magnetoencephalography study in human beings (158) and a near-infrared spectroscopy study applied on the frontal cortex (159). An exhaustive review on focal abnormalities in idiopathic generalized epilepsy (IGE) has been recently published (160). All these findings support the conceptual transition from "primarily generalized epilepsy," (implying that all brain regions simultaneously would generate GSWD) to seizures "originating within and rapidly engaging, bilaterally distributed networks" of cortical and subcortical regions (15).

Concerning the role of subcortical structures, in patients with IGE, it has been shown that both the anterior nucleus of thalamus (ANT) and the centromedian/parafascicular (Cm/Pf) nucleus (which provides diffuse inputs to the cortex) are activated during GSWD; the activity of the cortico-reticular Cm/Pf preceded that of the ANT, suggesting that the $\mathrm{Cm} / \mathrm{Pf}$ is involved in GSWD initiation or early propagation, while the ANT in its maintenance (161).

Recent studies have used fMRI to investigate whether restingstate FC between thalamus, basal ganglia, and DMN areas is altered in patients with IGE, even during GSWD-free periods of brain activity (Figure 4). Wang et al. (162) used ICA to map RSNs in 16 patients with IGE and 16 HC. They found that the DMN had simultaneously reduced FC within the anterior cingulate cortex, but increased connectivity in the precuneus. Moreover, they found widespread connectivity reductions in prefrontal, sensorimotor, and even auditory cortices (162). Reduced resting-state FC

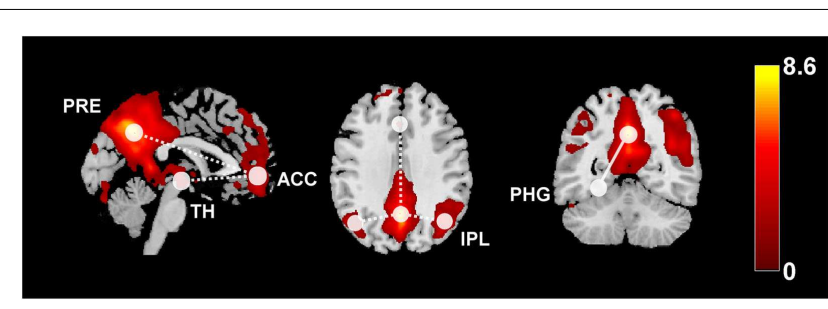

FIGURE 4 |This diagram summarizes the functional connectivity (FC) changes in patients with idiopathic generalized epilepsy compared to healthy controls. The color map shows the default-mode network (z-scores) derived from independent component analysis or RS-fMRI data overlaid on a standard single-subject anatomy (Montreal Neurological Institute space). Widespread FC reductions were found within the DMN (dashed lines), as well as between anterior DMN and the thalamus.

Increased FC related to increased disease duration has been observed between posterior DMN regions and the parahippocampal gyrus (solid line) $\mathrm{ACC}$, anterior cingulate cortex, IPL, inferior parietal lobule, PRE, precuneus, $\mathrm{PHG}$, parahippocampal gyrus, $\mathrm{TH}$, thalamus.

between frontal areas and the rest of the DMN was later confirmed (163). An important question is whether these changes in DMN connectivity are meaningfully related to clinical information, e.g., disease duration or responsiveness to medication. Of note, in both aforementioned studies, there were significant correlations between RS-FC and disease duration: the reduction in connectivity was inversely correlated to disease duration, indicating that long-standing epilepsy leads to progressive disruption of DMN integration. Interestingly, a study of structural and FC in 26 IGE patients and $\mathrm{HC}$, showed that the degree of coupling between functional and structural connectivity networks is decreased, and exhibited a negative correlation with epilepsy duration in patients (164).

Other RSNs can be affected in patients with IGE, reflecting specific cognitive impairment when compared to controls. A seed-based RS-FC study in 14 patients with IGE showed that attention network is impaired even in interictal periods, and that this impairment is related with the disease duration (165).

One study in 60 IGE patients specifically addressed the question whether pharmacoresistance was correlated with RS-FC changes in the DMN (166). DMN connectivity was reduced in the IGE group compared to $\mathrm{HC}$, and the strongest decrease was found in those patients that were resistant to valproate. Finally, a recent study directly addressed RS-FC within the thalamo-cortical system (167), finding decreased RS-FC between thalamus and anterior DMN. Collectively, these studies suggest that there is a loss of functional integration in the thalamocortical and default-mode system of the brain in IGE, even outside the GSWD. Although small sample size and heterogeneous methodology limit "generalization," the abnormal RS-FC patterns found in IGE so far could serve as endophenotypes of different IGE syndromes, and thus inform clinical diagnostics. Importantly, the confounding effect of anti-epileptic drug on dysconnectivity needs to be further elucidated.

The most frequent IGE syndrome is juvenile myoclonic epilepsy (JME), where seizures are characterized by myoclonic jerks of the upper limbs, often triggered by cognitive inputs. Several RS 
and task-related functional studies have shown an impairment of connectivity among supplementary motor area and the rest of the brain (168-170), suggesting that this structure may represent the anatomic basis for triggering motor seizures in JME. JME patients have often personality characteristics suggestive of a frontal lobe dysfunction (e.g., risk-taking behavior, dysexecutive syndrome). A task-related FC study in JME patients (171) shows that patients with ongoing seizures learn less from previous experiences compared to seizure-free patients and to controls.

\section{Pediatric syndromes}

Numerous EEG-fMRI studies have been conducted on pediatric syndromes [for review, see in Ref. (172)]. Several studies in Lennox-Gastaut syndrome (173-175) have shown hemodynamic involvement of brainstem, thalamus, and basal ganglia during paroxysmal fast activity and slow spike-and-wave discharges, underlying the importance of cortical-subcortical networks in Lennox-Gastaut syndrome. A group-analysis study in patients with myoclonic-astatic-epilepsy (176) showed that GSWD are related not only to a thalamo-cortical network (commonly found in IGE), but also to brain areas associated with motor function, suggesting that the involvement of these structures may predispose to the typical myoclonic jerks observed in this syndrome.

Concerning idiopathic focal epilepsies of childhood, these comprise a broad spectrum of phenotypes showing an overlap with each other, from benign childhood epilepsy with centro-temporal spikes (BECTS) to more severe seizure and cognitive disorders, like atypical benign partial epilepsy (ABPE), continuous spikes and waves during slow sleep (CSWS), and Landau-Kleffner syndrome. In patients with BECTS, EEG-fMRI studies have revealed focal spike-associated BOLD signal changes in the sensorimotor cortex, well corresponding to spikes localization, and typical seizure semiology (177-180). In patients with CSWS, a consistent neuronal network including both cortical and subcortical structures was described with positive BOLD signal changes in the perisylvian region, insula, cingulated cortex, and thalamus, and negative BOLD signal changes in the DMN areas and caudate nucleus (181). Source analysis of the simultaneously recorded EEG in these patients allowed differentiating initiation from propagation of epileptic activity in these common networks. The importance of assessing sleep state when studying networks is given by the report of a patient, whose centro-temporal spikes were recorded during wakefulness and sleep. BOLD response during wakefulness showed a focal activation concordant with the spike topography, whereas BOLD response to the same event during sleep showed the involvement of a thalamic-perisylvian neural network similar to the one previously observed in patients with CSWS, suggesting a common sleep-related network dysfunction even in cases with milder phenotypes (182).

A single-subject and group-analysis study (183) on patients with ABPE demonstrated that this syndrome is characterized by patterns similar to studies in rolandic epilepsy (focal BOLD signal changes in the spike field) as well as patterns observed in CSWS (distant BOLD signal changes in cortical and subcortical structures), thereby corroborating the concept that idiopathic focal epilepsies of childhood form a spectrum of overlapping syndromes.
An EEG-fMRI study in thirteen patients with ring 20 chromosome syndrome (184) shows specific networks involved by different interictal and ictal events of interest, suggesting that some hemodynamic networks are the expression of epilepsy-related cognitive and behavioral deficits typical of ring 20 chromosome syndrome, whereas others can be common to other syndromes with neurobehavioral regression.

\section{INTRACRANIAL EEG STUDIES}

The indication for video-iEEG monitoring is the absence of a unique focal hypothesis regarding the source of the patient's seizures (obtained with non-invasive investigation), or the need for cortical mapping of the epileptogenic cortex vs. eloquent cortex (7). Therefore, intracranial electrodes often sample from more than one lobe, although their spatial sampling remains limited and needs to be targeted using all available clinical and paraclinical information. Subdural grids allow dense sampling of the cortical convexity while intracerebral depth electrodes are able to reach deeper structures (e.g., medial temporal structures); combinations of both techniques are feasible. Therefore, iEEG studies represent a unique opportunity to investigate seizure networks in human beings with optimal temporal and excellent spatial resolution.

The concept of the seizure-onset zone as a single, circumscribed brain region implies that, assuming that intracranial electrodes sample this region, ictal iEEG activity should invariably start there. Careful observation of ictal iEEG recordings, however, reveals that this is not always the case. Rather, there are patients in whom clinically indistinguishable seizures seem to start at any of two or more distinct brain areas (100). Observations such as this were one of the major factors spurring the interest in considering seizuregenerating brain regions as distributed networks. Therefore, the seizure-onset zone could be seen as the particular regions with the lowest seizure threshold while other regions could also give rise to independent seizure onsets, which explains the need to consider more than the sole seizure-onset zone for estimating the epileptogenic zone. In an attempt to quantitatively analyze seizure-onset patterns, Bartolomei and colleagues (185) developed the epileptogenicity index (EI), which takes into account the transition of iEEG activity toward higher frequencies (a general observation of ictal iEEG patterns) together with the delay in which the transition is observed compared to the ictal onset. This approach has revealed that in a significant portion of TLE patients, the medial and lateral temporal lobe display similar EI, implying that both structures could equally subtend seizure generation. Also of interest, some patients with what seemed like TLE before implantation actually displayed the highest values of EI in the fronto-orbital, opercular, or insular cortex rather than the temporal lobe, and these patients had poorer outcomes after resective surgery, suggesting that they harbored more distributed seizure-generating networks not easily amenable to full resection (186). The number of brain regions with a high EI increases with the duration of epilepsy, suggesting that epilepsy networks may extend over time as a result of plasticity triggered by pathological activity $(185,186)$.

The same authors analyzed the neurophysiological correlates of alterations of consciousness in TLE (187). They found that alteration of consciousness was associated with increased broadband synchronization in a network of structures, which were 
mainly extra-temporal, including the thalamus, cingulate cortex, and parieto-temporal association cortex. Consciousness was preserved as long as excessive synchrony was confined to the temporal lobe. Similarly, loss of consciousness in parietal seizures was associated with widespread parietal and frontal synchronization (188). The authors framed these observations into the context of the global workspace theory, in which the sustained synchronization of neuronal activity in widely distributed modules renders perceptions, memories, and intentions available to consciousness (189). This work rejoins observations made with single photon emission computed tomography that temporal lobe seizures causing altered consciousness were associated with widespread cortical and subcortical blood-flow alterations (190). That group later showed increases in the power of delta oscillations in the frontal and parietal association cortices during seizure-related loss of consciousness (191). Results from studies in a rat model of complex partial seizures suggest that these widespread changes are caused by transient alteration of activity in the subcortical septal nuclei (192), implying that the widespread effects of temporal lobe seizures on cortical networks could be mediated indirectly via the midline arousal structures (193).

Measures of directed connectivity in seizure networks are starting to reveal the internal organization of the individual nodes that make up the network. To date, most iEEG studies use mathematical approaches to determine the direction of connections. For instance, using focal cortical dysplasia as a model of a circumscribed seizure-onset zone and applying partial directed coherence analysis, Varotto et al. (12) found that the focal dysplasia indeed acted as the initial generator of ictal activity, as evidenced by its greater out-degree both interictally, pre-ictally, and during ictal onsets [the out-degree is a summary measure of the influence of one network node on all the others (194)]. Cortical-areas remote from the morphological lesion could also be involved in the onset or early propagation of ictal high-frequency activity and could thus represent secondary foci. Wilke et al. (195) used frequency-bandspecific betweenness centrality, a graph theoretical measure of the "importance" of a node in network pathways, to demonstrate a significant overlap between the intracranial electrodes showing the highest betweenness centrality and the seizure-onset zone delineated visually by clinical neurophysiologists, as well as the resected cortical area. That correspondence was present both during ictal and interictal recordings and was highest for gamma-band frequencies. In addition, the analysis also revealed nodes with high betweenness centrality that had not been clinically identified as part of the seizure-onset zone. Van Mierlo et al. (196) showed that the single intracranial electrode with the highest out-degree during seizure onsets was included in the clinically defined seizureonset zone as well as the resection area in all of eight patients. These first findings suggest that analyzing epileptic networks in the framework of graph theory, taking into account the direction of connections between nodes in the network, can help clinicians delineate the primary drivers from secondary nodes in seizure nodes [see also in Ref. (197) for a review]. In the near future, we expect that the tools of graph theory will be applied more generally to iEEG data to describe more fully the spatio-temporal dynamics of seizure networks. Another unique perspective could be offered by the analysis of simultaneous recordings of iEEG and fMRI (198,
199) to combine the spatial resolution of iEEG with the mapping of whole-brain BOLD changes related to epileptic activity. This could allow bridging the poorly understood gap between increased iEEG connectivity and reduced BOLD connectivity within epileptic networks (108).

\section{Micro-electrode studies in human beings}

Another potential breakthrough in the investigation of epileptic networks could stem, in a somewhat paradoxical fashion, from micro-electrode array recordings, which revealed new insights on the pathophysiology of epilepsy. Schevon et al. (200) inserted arrays comprising of 96 electrodes arranged in a 4-by-4-mm square pattern in the putative seizure-onset zone allowing to record single unit activity in cortical layers 4 and 5 as well as recording the local-field potentials. They showed that there is a sharp delineation (at a sub-millimetric scale) between corticalareas involved in intense hypersynchronous firing (the hallmark of ictal activity, based on animal studies) and adjacent areas with only mildly increased firing rate and synchrony. Crucially, visual inspection of the iEEG alone did not allow distinguishing between what the authors termed the seizure core and its (presumably) inhibitory penumbra. The same investigators further proposed that ictal high-frequency oscillations phase-locked to the lower-frequency, high-amplitude ictal iEEG recorded by standard intracranial electrodes might represent a signature of increased firing in the seizure core (201). These new findings open the possibility of investigating neuronal firing in distributed seizure networks using conventional iEEG electrodes, without the need for micro-electrode arrays. Future work building on these exciting findings will likely increase our understanding of the ways in which seizures alter normal neuronal firing across the nodes of the involved networks.

\section{Direct electrical stimulation studies}

Direct electrical stimulation (DES) in epileptic patients consists of administering electrical currents to the brain tissue in order to transiently influence or perturb its function. A technique almost as old as epilepsy surgery, it has mostly been used to probe the function of the cortex directly underlying or surrounding the stimulation site (202-205). In that context, DES is generally delivered at high frequencies (e.g., 50-60 Hz) for a few seconds with the aim of inducing clinical changes in the patient (206). More recently, DES has also been used to investigate FC; in that case, single stimulation pulses are delivered at low frequencies (e.g., $1 \mathrm{~Hz}$ ) and the readout consists of time-locked perturbations in the activity of points distant from the stimulation site (cortico-cortical evoked potentials, CCEPs) (207). An interesting aspect of DES-based FC assessments is that they are directed, i.e., the effect of stimulation at site A on site $B$ is not necessarily symmetrical with the effect of stimulating B on A (Figure 5). There is an intuitive appeal to this "hands-on" interventional approach to reveal directional connectivity. Evoked effective connectivity was found to correlate with FC measured by resting-state fMRI (22) as well as with anatomical connectivity probed by diffusion tensor imaging (208). It has been pointed out, however, that DES can activate axons in the antidromic as well as the orthodromic direction, and could also stimulate fibers de passage, an important caveat to keep in mind when interpreting the directionality information provided by these data (209). 
A
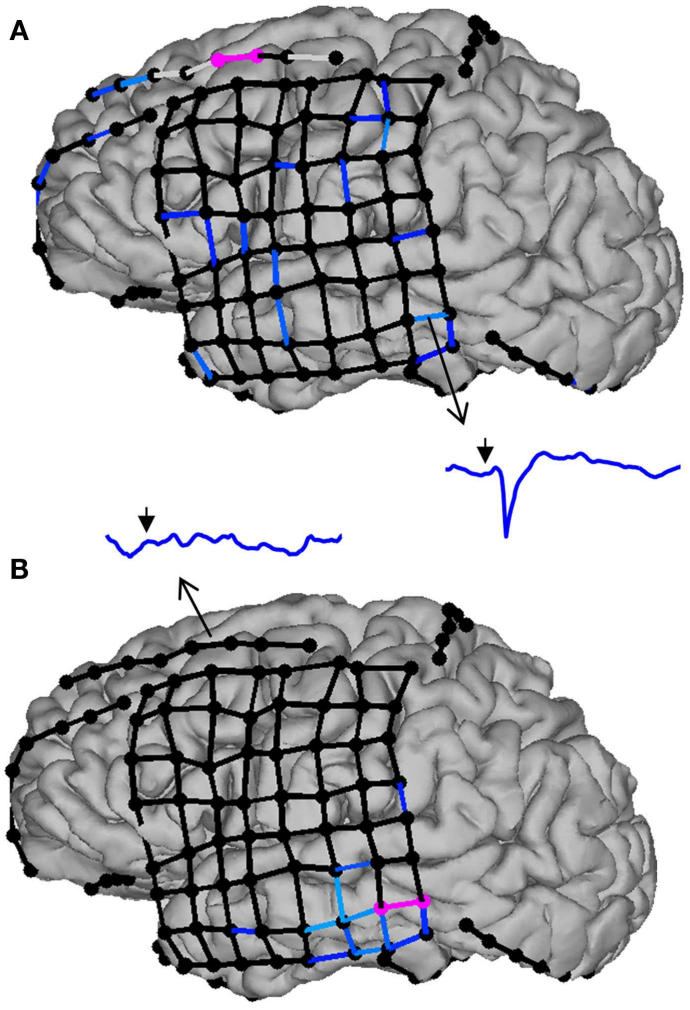

FIGURE 5 | Evoked effective connectivity reveals the directionality of neural connections in the human brain. In this example, subdural electrodes are represented by circles, and CCEP responses as lines linking bipolar electrode pairs. Missing (e.g., artifacted) data are indicated by light gray lines, sub-threshold (non-significant) responses by black lines, and significant responses by progressively lighter shades of blue.

(A) Stimulation of the middle frontal gyrus (electrode pair colored in pink) triggers widespread responses in the frontal and temporal lobes, including the middle temporal gyrus (inset: CCEP waveform from $50 \mathrm{~ms}$ before to $250 \mathrm{~ms}$ after stimulation; the arrow indicates the time of stimulation). By contrast, stimulation of the middle temporal gyrus (B) does not evoke any significant response in the frontal lobe, illustrating that effective connectivity between remote brain structures is not necessarily reciprocal.

This highlights the importance of aiming at obtaining multimodal functional and structural information to better understand brain connectivity and dynamics.

Evoked effective connectivity has revealed strong intralobar connectivity in the temporal and frontal lobes, as well as connections between the frontal and temporal lobes that are more prominent in the frontal-to-temporal than in the temporal-to-frontal direction $(210,211)$. An intriguing aspect of these studies is the observation that, whereas interhemispheric connections between the frontal lobes are relatively common, temporal-temporal connections appear sparse, being observed in $<20 \%$ of patients (211). This begs the question of which neuronal pathways are responsible for bitemporal synchronized spiking as well as the propagation of seizures from one temporal lobe to the other one (212). Recently, David et al. (213) generalized this approach offering to develop an atlas of evoked effective connectivity that would eventually allow, through data sharing, sampling most of the human brain's volume.
Direct electrical stimulation has also been used to specifically evaluate epileptic networks, the general idea being that the responses of remote sites to stimulation of epileptogenic cortex (214) or the responses of epileptogenic cortex to stimulation of remote sites (215) differ from those involving only normal brain tissue. Interestingly, the network of brain areas that respond to DES of the seizure-onset zone overlaps partially but not completely with the areas of ictal propagation, suggesting both that seizures propagate sequentially through multiple nodes in the network and that some existing connections between the seizure-onset zone and distant brain areas "shut down" during seizures (216). Further research combining iEEG and DES, as well as integrating these techniques with fMRI and high-density non-invasive electromagnetic recordings, will improve our understanding of the physiology of seizure networks.

\section{WHAT WE CAN LEARN FROM ANIMAL MODELS}

Recording the activity of any node suspected to be determinant in the disease is not feasible in human beings, contrarily to animal research. Moreover, animal-related technologies offer the possibility to desiccate and manipulate cellular and molecular components of such networks, as well as scrutinizing the associated structural and functional alterations. A great perspective in pathological networks study is detecting features associated with the risk of recurrence after a first seizure as well as predicting the evolution toward pharmaco-resistance.

Animal models allow studying networks connectivity and recording the underlying brain activity with high spatial coverage and resolution (217), and addressing the process of epileptogenesis and ictogenesis, including their molecular and genetic mechanisms at cellular and subcellular levels (218-222). Imbalance between excitation and inhibition might not only occur at the local microscopic level $(223,224)$, but could also reflect dysregulation of excitatory and inhibitory neuronal interactions at a larger (network) scale. Recent evidence emphasizes the modifications of the network dynamic, or network configuration that characterizes, and sometimes precedes or even predicts a seizure. Network analysis could be a powerful tool to more precisely define the different epilepsies and develop new treatments that target networks, instead of focal activity $(11,100)$.

In animals and human beings, focal onsets have been identified in generalized epilepsy, and complex large-scale network involvement has been shown in focal epilepsies $(8,11,14)$. Spontaneous epileptic disease occurs in animals, as in the case of the genetic absence epileptic rats of Strasbourg (GAERS) or in the WAG/Rij rats (225-227); other models studied are epileptic conditions induced by - mainly - chemical or electrical interventions (220). A major animal model of TLE is the kainate, or pilocarpine, model of hippocampal sclerosis (HS) (228-232). Kainate, a glutamatergic agonist, is injected either in the hippocampus or intraperitoneally. It is suspected that the kainate has a tropism for the hippocampus, which led several authors to consider that the kainate induces specifically a HS. Yet, the mechanisms by which kainate induces an epileptic activity is still debated; the immune system and leakage of the blood-brain barrier have been cited as critical for the expression of the disease $(233,234)$. Hence, it is not excluded that systemic kainate may have diffuse effects on the brain. 
Models of focally induced epileptic disorders might avoid this limitation. One of them, electrical kindling, triggers focal epileptic activity using focal electrical stimulation in accordance with standard stimulation parameters, e.g., duration of the stimulation, frequency, and intensity of the stimulus $(220,235,236)$. The emergence of a distant pathological activity can be related to remote effects of the focally induced epilepsy, and not to the direct diffuse effects of the electrical or chemical triggers. Electrical stimulation, in particular of the performant-path, has also been described as a model of induced status epilepticus $(237,238)$.

\section{CONNECTIVITY STUDIES IN ANIMALS}

Electrophysiology can assess connectivity and RS networks in animal models of epilepsy by recording several brain regions simultaneously. The great advantage is that the signal can be directly linked to neuronal activity. Using intrahippocampal recording in a rat model of induced TLE, Wang et al. (239) showed that neuronal pairs presented a decreased FC prior to the status epilepticus induced by an intraperitoneal injection of pilocarpine. Using Graph Theory measures in an in vitro $\mathrm{Mg}^{2+}$-free model of hippocampal epilepsy, Gong et al. (240) reported the modifications in network configuration that appear in parallel to epileptiform discharges. More interestingly, they revealed that the changes in network configuration appeared before and lasted longer than the epileptiform discharges (240). These two observations suggest that the classical ictal activity, i.e., the presence of spikes in the EEG, could be the resultant of network reconfiguration, i.e., it could even be an epiphenomenon of a more profound alteration in brain connectivity, indicating that it could be possible to identify certain network alterations as a biomarker of epilepsy. Such studies aimed at identifying markers of an upcoming ictal activity and have mainly looked at the local activity changes (241). Knowledge on remote involvement is sparse. Recent works (224) showed structural alterations remote from the focus, but only a few evidence of distant, abnormal neuronal activity exists (242). Major advancement has been made to record as many neurons or neuronal populations as possible at the same time (145,243-248); this shows the feasibility to investigate large-scale networks in animal models with high temporal and spatial resolution (Figure 6). Their combination with effective connectivity measures (25) will help to better understand the hierarchical organization of epileptic networks. Gong et al. (240) demonstrated the leading activity of pyramidal cells over granular cells in an in vitro model of TLE, illustrating the utility of effective connectivity in the field of epilepsy.

Research on animal models of epilepsy has been dominated by invasive electro-physiology technique. Recently, the combination of EEG and fMRI has emerged with interesting results, such as those reported by Englot et al. (192), where they describe how a partial limbic seizure lead to neocortical slow-wave activity; yet, technical issues makes difficult to obtain combined EEG-fMRI in awake animals. As in Englot et al. (192), fMRI could possibly be a powerful in vivo screening method for anatomical regions that could then be more deeply investigated with EEG.

Using fMRI, Mishra et al. (249) showed that rats submitted to traumatic brain injury through left parietal fluid percussion presented a decreased correlation coefficient between the left parietal cortex and other brain regions. Dysfunctional activity in the

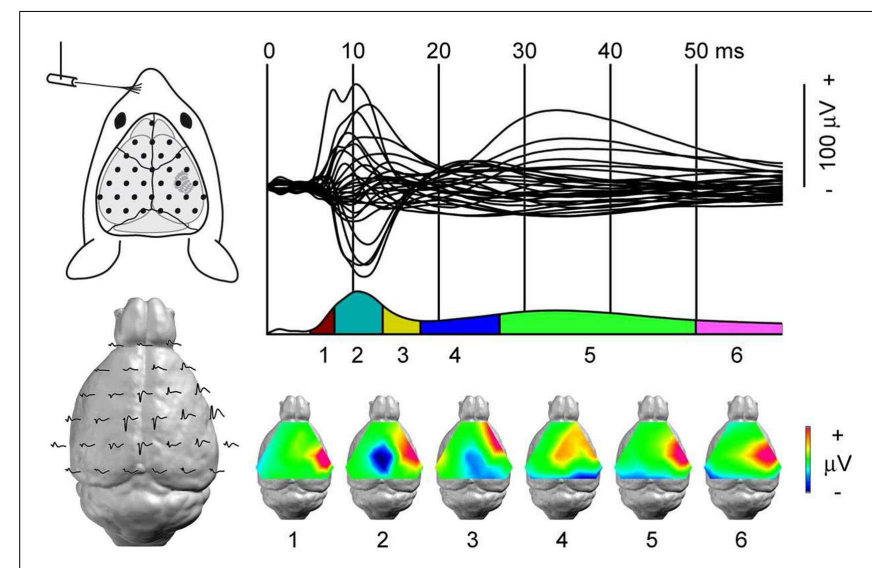

FIGURE 6 | Dynamic of somato-sensory network mapped with high-density EEG. Somato-sensory evoked potential (SEP) from left whisker stimulation. Top left: each black dot represents the position of one recording electrode; the most anterior one is ground. Top right: 31 electrode traces displaying the SEP with sub-milliseconds resolution. Bottom left: the same electrode traces represented over the mouse brain. In the lissencephalic mouse brain, dipoles are estimated to be generated below the recording electrodes. Bottom right: segmentation of the SEP in six stable configurations of potential maps. The technique's high spatial and temporal resolutions identify the first component, somato-sensory barrel field activity, followed by motor cortex and contra-lateral somato-sensory areas recruitment within a few milliseconds. Adapted from Megevand et al. (243) with permission.

left parietal cortex, as highlighted by the decreased correlation coefficient could have been expected, yet the pattern of resting BOLD-fMRI connectivity showed that only certain regions were specifically affected, namely the left hippocampus and the contralateral parietal cortex. This illustrates that BOLD-fMRI can be used to identify secondary dysfunctional brain regions in rodents following a proepileptogenic injury (249). The same group investigated with fMRI the FC in WAG/Rij rats (250) and found an increased correlation between brain areas suspected to be involved in seizures when compared to non-epileptic rats; more importantly, this increase was observed outside of the ictal periods. Choi et al. (251) performed a FC study using the ${ }^{18}$ fluorodeoxyglucose positron emission tomography (PET) signal in a rat model of TLE. They revealed the decreased correlation of several pairs of brain structures, most of them included left amygdala and left entorhinal cortex (251). Hence, despite the systemic injection of pilocarpine, the affected network appeared to be mainly restricted to the left hemisphere (251). It would have been very interesting to see if the electro-physiological counterpart of such functional deficit was also restricted to one hemisphere, yet no EEG recording was reported. Asymmetry in the central nervous system is well recognized, e.g., asymmetry of the temporal lobes, but the reason why the left hemisphere appears to be more functionally altered in this rat model of TLE is unclear, although electro-physiological experiments suggest that the left hemisphere is indeed more prone to develop epileptic discharges (252). The authors claimed that the PET images were acquired in the interictal period, but no EEG recording was used (251); yet, if true, this would suggest that epileptic animals can be identified as such on the basis of the FC 
of particular networks outside of any ictal activity. These studies (249-251) indicate that the pathological process in these rats is ongoing: the epileptic brain is not suffering from epilepsy only during seizures.

The anatomical basis of FC is largely unclear. Zhou et al. (253) nicely investigated the anatomical substrate and plasticity of such connections. They observed that after partial posterior callosotomy of wild-type rats, the FC of the auditory and visual cortices decreased at day 7 and returned to baseline at day 28, whereas this decrease was still present in rats submitted to complete callosotomy (253). The authors concluded that it could be possible to identify the anatomical basis of FC, and that these functional connections were also capable of plasticity. This is an important proof-of-concept: it is possible to identify morphological substrate of functional connections and manipulate them.

\section{DIFFERENTIAL INVOLVEMENT OF SPECIFIC BRAIN REGIONS IN ANIMAL MODELS OF GENERALIZED EPILEPSY}

Different rat models of generalized absence epilepsy have been studied and all share the presence of the characteristic SWDs (254, 255). Using combined EEG-fMRI in WAG/Rij rats, Mishra et al. (250) demonstrated that during SWDs, the associated fluctuations in the BOLD signal were specific to certain brain regions. Indeed, the somato-sensory barrel field showed an increase, whereas the striatum showed a decrease in the BOLD signal and cerebral bloodflow $(225,250)$. On the other hand, the local-field potential (LFP) and the multi-unit activity (MUA) were increased in both regions (225). Vascular steal or dopamine-regulated blood volume could account, at least in part, for this lack of matching between BOLD signal and CBF on the one hand and LFP and MUA on the other hand (225). An earlier study using surface and deep EEG recordings in the same rat-model showed that these rats shared a similar focus located in the ventrolateral part of the somato-sensory cortex (SC) (145). More importantly, the authors observed that the ictal activity of the cortical focus preceded the one in the thalamus, suggesting that the cortex was leading the thalamus (145). Nersesyan et al. (256) investigated the relation between SWDs and CBF in the same animal model. They showed that regions involved in SWDs, i.e., SC, presented a 1 - to 2 -s delayed increase in CBF during a SWD, whereas this increase did not appear in regions not involved in the SWDs, such as primary visual cortex (256). In a parallel work using the same animal model of absence epilepsy, they observed that the BOLD signal was not equally modified across brain regions during a SWD (257): the somato-sensory and motor cortices, as well as subcortical regions, i.e., thalamus, basal ganglia, and brainstem, showed an increased BOLD signal, whereas other regions such as the occipital cortex did not show such a modulation of the signal (257). Again, the increase in the BOLD signal appeared with a lag of a few seconds after the electro-physiological SWDs (257). This finding is in contrast with a work by Desalvo et al. (258), in which they used a rat model of generalized tonico-clonic seizures induced by injection of iv bicuculline, and observed that BOLD increased significantly in primary and secondary somato-sensory cortices, as well as in primary auditory cortex and thalamus before the onset of electro-physiological seizures. The role of the SC in initiating GSWDs was further investigated through inactivation of this cortical region in GAERS animals (259). The pharmacological inactivation of the SC with the sodium channel blocker tetrodotoxine prevented the spike-and-wave activity; yet unilateral application of the drug did not completely abolish the abnormal contra-lateral oscillations. On the whole, these studies highlight the importance of abnormal focal brain activity as a potential trigger of generalized seizures (258). The identification of interacting yet independent nodes within a network of suspected generalized epilepsy is a major advance in epilepsy research. Indeed, it will permit to refine the therapeutic intervention toward the manipulation of one particular and decisive node.

\section{SHORT-RANGE AND LONG-RANGE NETWORK MODULATIONS IN ANIMAL MODELS OF FOCAL EPILEPSY}

Different animal models of focal epilepsy exist (220), such as the kainate- or pilocarpine-models of MTLE $(228,229,260)$, posttraumatic epilepsy $(261,262)$, or electrical kindling $(227,263)$. Despite an initially focal insult, recent evidence (e.g., 242) shows that remote brain areas become affected by the pathological activity of the epileptic focus.

The induction of a focal epileptic syndrome in a rat model of generalized epilepsy allows better understanding how these two entities interact. Carcak et al. (227) took advantage of the fact that absence epilepsy may increase the resistance to limbic seizures. They investigated the role of the cortico-thalamo-cortical circuitry, involved in SWDs, in the development of limbic seizures induced by unilateral electrical stimulation of the rat amygdala. Whereas control rats, i.e., those without absence epilepsy, presented all convulsive epileptic seizures following amygdala electrical stimulation, rats suffering from absence epilepsy did not (227). In order to understand how the circuit involved in absence epilepsy could affect the one of TLE, the authors investigated the spontaneous activity in the reticular thalamic nucleus (RTN), known to be involved in the slow-waves discharges that characterize absence epilepsy (227). Remarkably, the electrical stimulation of the amygdala had a different effect on the mean firing frequency of neurons of the RTN: in not-stimulated animals, there was no significant difference between epileptic and non-epileptic rats, whereas the increase after stimulation was higher in epileptic rats when compared to non-epileptic rats (227). This suggests first that the development of an epileptic focus alters the activity of neurons in the RTN and second that this alteration depends on the activity before the induction of the epilepsy. The use of Wistar rats as controls for GAERS rats in that study is commonly accepted, but could still be questioned; yet the conclusion would still remains the same: the effects of an epileptic focus seem to depend on the brain state in which it is being established. It would hence be interesting to investigate how an epileptic focus affects a given network, but also how a particular network configuration can modulate the effects of an epileptic focus. The involvement of the thalamus in propagation of temporal lobe seizures has already been the scope of several studies $(156,264)$. If the thalamus has a major role in the generation of SWDs (227), this could highlight the relevance of studying the interaction between hippocampus and thalamus, in the context of focal epilepsies. 
Hippocampal sclerosis is a frequent lesion that has been deeply investigated, although, most of the works conducted local, intrahippocampal recordings. Yet, recent publications have shown the involvement of remote brain areas. Using 16 bipolar deep electrodes in the pilocarpine rat-model of HS, Toyoda et al. (247) showed that the initial focus varied from one seizure to another in each individual rat. The subiculum, the dorsal and ventral hippocampus, and the amygdala were the regions where seizure onsets were most often recorded. All regions could be considered as belonging to the same network; indeed, an interesting observation is that most seizures were convulsive, and this did not depend upon where the seizure started (247). This suggests that the involved network is more determining than the seizure-onset zone for the clinical expression of a seizure. Long-range modifications in the kainate mouse-model of TLE were also observed. It has been shown that non-injected hippocampus presented indeed morphological alterations, notably in the expression of the neuropeptide-Y, which is known to modulate neuronal activity $(265,266)$, and electro-physiological changes, such as significant decrease in the power of the theta frequency band (265). In vitro, Khalilov et al. (267) demonstrated that a mirror focus in the contra-lateral hippocampus appears after 10-15 successive applications of kainate in the ipsilateral hippocampus. These findings are in line with the hypothesis that an epileptic focus leads to permanent electrophysiological and morphological modifications in remote brain areas (268-270). Other works have also stressed the possibility that subcortical brain regions, such as the basal ganglia, could influence or even inhibit the progression of an ictal activity originating from the temporal lobe $(271,272)$.

Evidence of distant brain involvement arises also from electrically induced epilepsy. For instance, during hippocampal seizures induced by electrical stimulation in rats, the frontal neocortex presented a parallel modification in spontaneous activity, i.e., fast polyspike activity when the seizure was generalized and slow oscillations when it was partial (242). This example illustrates that distant brain areas are affected even after a few or only one focal epileptic seizure. It would be extremely interesting to study how this involvement evolves in a chronic disease.

On the whole, evidence exists that other brain areas are recruited in propagation or in inhibition of the seizure spread. Hence, the epileptic threshold does not seem to depend only on the imbalance between excitation and inhibition within the focus, but could also be determined by the intricate interactions between the components of a given network.

\section{EXPERIMENTAL THERAPEUTIC INTERVENTIONS ON THE EPILEPTIC NETWORK}

Conceiving epilepsy as a network disease has therapeutic consequences. The classical view is to modulate the activity of the so-called epileptic focus, or seizure-onset zone, in order to control the disease. Yet, any node of an epileptic network could possibly be a target. In this sense, open-loop or closed-loop devices, either through electrical or optogenetic stimulation, are promising tools for generalized (217) as well as for focal epilepsy $(273,274)$. Major work has shown that it is possible to identify critical nodes in a given epileptic network: the modification of their activation - mainly inhibition - could help to control, or even stop an ictal activity. Paz et al. (274) showed in a rat model of cortical epilepsy that the inactivation through optogenetics of the thalamic ventrobasal nucleus could stop an ongoing seizure. In the same line, Langlois et al. (264) showed in an in vivo model of TLE that DBS of the ipsilateral parafascicular nucleus of the thalamus (PF) stopped the ongoing hippocampal paroxysmal discharges (HPD), while higher current intensities were needed to stop the HPD if DBS was applied to neighboring areas (264), illustrating the specificity of PF in controlling HPDs. The anterior thalamic nucleus (ANT) appears also to be involved in control or spread of epileptic activity of mesial temporal onset (156). Ablation or electrical stimulation of ANT increases the epileptic threshold $(263,275-277)$; yet, opposite results have also been observed (278). On the whole, ANT is a recognized target for refractory epilepsy, although mechanisms by which manipulation of the ANT increases epileptic threshold are poorly understood. Use of animal research and the possibility to identify how the activity of ANT may modulate epileptic activity at remote sites, e.g., with the use of effective connectivity measures, is crucial to tailor therapeutic interventions. Such recent evidence shows that the manipulation of the primary epileptic focus does not seem to be the only possibility to achieve the control of an epileptic disease. The thalamus in particular, and other subcortical regions as well (272) have been identified as major targets for epileptic network modulation culminating in clinical applications in the form of DBS of ANT in focal epilepsies (279).

\section{CONCLUSION}

With increasingly complex methodological strategies and an everincreasing wealth of possible approaches, the study of brain connectivity and its neuroscientific and clinical correlates are very promising. Nevertheless, the application of connectivity techniques for diagnostic or prognostic purposes requires further studies to be firmly grounded by invasive studies and sufficient follow-up investigations before it can be reliably applied to the clinical management of individual patients. Combining functional techniques can lead to the achievement of complementary information for improving each single technique.

Focal epilepsies, despite focal epileptogenic zone, are diseases affecting the whole brain: altered large-scale FC is reflected in neuropsychological features of individual specific syndrome. Hippocrates ( 400 years b.c.) considered epilepsy as a systemic disease, centered in the brain, due to an altered "defluxion of cold phlegm" through the body. In more recent times, the concept of epilepsy as "focus disease" has been largely developed (280-282), whereas in the last decade it has shifted to a "brainnetwork disease" (15). In parallel to the "brain-network" concept of epilepsy, psychiatric and neurological co-morbidities, such as strokes, dementia, and migraine are more and more defined. Interestingly, somatic co-morbidities have also come to light, since several medical conditions, such as cardiac, gastrointestinal, and respiratory disorders, are often associated with epilepsy (283). These findings may lead to re-consider epilepsy as a "systemic disease," this time with the diagnostic and therapeutic 
knowledge obtained recently by ground-breaking work on network analysis.

Concerning "generalized" epilepsy, neuro-imaging, and especially connectivity studies have allowed considering them as focal brain disorders with fast bilateral discharge propagation. This concept leads to the idea that focal and generalized epilepsies are the two extremes of a single spectrum and to a possible new way of studying mechanisms of AED: do they have an effect on particular nodes of a network where receptors are more expressed? Is it possible to detect an anatomical target to avoid generation/propagation of seizures, using disconnection or stimulation? For all these reasons, translational research in light of network analysis, based on fundamental science through animal experiments and clinical perspectives through human research, opens new opportunities to better understand the complexity of epilepsy and define new and more effective treatments for patients.

\section{ACKNOWLEDGMENTS}

Francesca Pittau is supported by the Swiss National Science Foundation (FNS SPUM grant 140332). Serge Vulliemoz is supported by grant FNS 141165 and the Gertrude von Meissner Foundation. Laurent Sheybani is supported by grant FNS 323530_158125). Frédéric Grouiller is supported by the Center for Biomedical Imaging of the Universities and Hospitals of Geneva and Lausanne, and EPFL. We thank Dr. Gaetano Cantalupo (Verona) for the thoughtful comments during the manuscript preparation.

\section{REFERENCES}

1. Hauser WA, Annegers JF, Kurland LT. Incidence of epilepsy and unprovoked seizures in Rochester, Minnesota: 1935-1984. Epilepsia (1993) 34:453-68.

2. Sander JW. The epidemiology of epilepsy revisited. Curr Opin Neurol (2003) 16:165-70. doi:10.1097/00019052-200304000-00008

3. Schuele SU, Luders HO. Intractable epilepsy: management and therapeutic alternatives. Lancet Neurol (2008) 7:514-24. doi:10.1016/S1474-4422(08) 70108-X

4. Bancaud J. Surgery of epilepsy based on stereotactic investigations - the plan of the SEEG investigation. Acta Neurochir Suppl (Wien) (1980) 30:25-34. doi:10.1007/978-3-7091-8592-6_4

5. Spencer S, Huh L. Outcomes of epilepsy surgery in adults and children. Lancet Neurol (2008) 7:525-37. doi:10.1016/S1474-4422(08)70109-1

6. De Tisi J, Bell GS, Peacock JL, McEvoy AW, Harkness WF, Sander JW, et al. The long-term outcome of adult epilepsy surgery, patterns of seizure remission, and relapse: a cohort study. Lancet (2011) 378:1388-95. doi:10.1016/S01406736(11)60890-8

7. Rosenow F, Luders H. Presurgical evaluation of epilepsy. Brain (2001) 124:1683-700. doi:10.1093/brain/124.9.1683

8. Laufs H, Hamandi K, Salek-Haddadi A, Kleinschmidt AK, Duncan JS, Lemieux L. Temporal lobe interictal epileptic discharges affect cerebral activity in "default mode" brain regions. Hum Brain Mapp (2007) 28:1023-32. doi:10. 1002/hbm.20323

9. Gotman J. Epileptic networks studied with EEG-fMRI. Epilepsia (2008) 49(Suppl 3):42-51. doi:10.1111/j.1528-1167.2008.01509.x

10. Fahoum F, Lopes R, Pittau F, Dubeau F, Gotman J. Widespread epileptic networks in focal epilepsies-EEG-fMRI study. Epilepsia (2012) 53:1618-27. doi:10.1111/j.1528-1167.2012.03533.x

11. Richardson MP. Large scale brain models of epilepsy: dynamics meets connectomics. J Neurol Neurosurg Psychiatry (2012) 83:1238-48. doi:10.1136/jnnp2011-301944

12. Varotto G, Tassi L, Franceschetti S, Spreafico R, Panzica F. Epileptogenic networks of type II focal cortical dysplasia: a stereo-EEG study. Neuroimage (2012) 61:591-8. doi:10.1016/j.neuroimage.2012.03.090
13. Engel J Jr, Thompson PM, Stern JM, Staba RJ, Bragin A, Mody I. Connectomics and epilepsy. Curr Opin Neurol (2013) 26:186-94. doi:10.1097/WCO. 0b013e32835ee5b8

14. Stefan H, Lopes da Silva FH. Epileptic neuronal networks: methods of identification and clinical relevance. Front Neurol (2013) 4:8. doi:10.3389/fneur.2013. 00008

15. Berg AT, Berkovic SF, Brodie MJ, Buchhalter J, Cross JH, Van Emde Boas W, et al. Revised terminology and concepts for organization of seizures and epilepsies: report of the ILAE commission on classification and terminology, 2005-2009. Epilepsia (2010) 51:676-85. doi:10.1111/j.1528-1167.2010.02522.x

16. Gotman J, Grova C, Bagshaw A, Kobayashi E, Aghakhani Y, Dubeau F. Generalized epileptic discharges show thalamocortical activation and suspension of the default state of the brain. Proc Natl Acad Sci U S A (2005) 102:15236-40. doi:10.1073/pnas.0504935102

17. Smith SM, Fox PT, Miller KL, Glahn DC, Fox PM, MacKay CE, et al. Correspondence of the brain's functional architecture during activation and rest. Proc Natl Acad Sci U S A (2009) 106:13040-5. doi:10.1073/pnas. 0905267106

18. Biswal BB, Mennes M, Zuo XN, Gohel S, Kelly C, Smith SM, et al. Toward discovery science of human brain function. Proc Natl Acad Sci U S A (2010) 107:4734-9. doi:10.1073/pnas.0911855107

19. Tomarken AJ, Waller NG. Structural equation modeling: strengths, limitations, and misconceptions. Annu Rev Clin Psychol (2005) 1:31-65. doi:10.1146/ annurev.clinpsy.1.102803.144239

20. Friston KJ, Harrison L, Penny W. Dynamic causal modelling. Neuroimage (2003) 19:1273-302. doi:10.1016/S1053-8119(03)00202-7

21. Granger CWJ. Investigating causal relations by econometric models and crossspectral methods. Econometrica (1969) 37:424-38. doi:10.2307/1912791

22. Keller CJ, Bickel S, Entz L, Ulbert I, Milham MP, Kelly C, et al. Intrinsic functional architecture predicts electrically evoked responses in the human brain. Proc Natl Acad Sci U S A (2011) 108:10308-13. doi:10.1073/pnas.1019750108

23. Astolfi L, Cincotti F, Mattia D, De Vico Fallani F, Lai M, Baccala L, et al. Comparison of different multivariate methods for the estimation of cortical connectivity: simulations and applications to EEG data. Conf Proc IEEE Eng Med Biol Soc (2005) 5:4484-7. doi:10.1109/IEMBS.2005.1615463

24. Smith SM, Miller KL, Salimi-Khorshidi G, Webster M, Beckmann CF, Nichols TE, et al. Network modelling methods for FMRI. Neuroimage (2011) 54:875-91. doi:10.1016/j.neuroimage.2010.08.063

25. Plomp G, Quairiaux C, Michel CM, Astolfi L. The physiological plausibility of time-varying Granger-causal modeling: normalization and weighting by spectral power. Neuroimage (2014) 97C:206-16. doi:10.1016/j.neuroimage.2014. 04.016

26. Bullmore E, Sporns O. Complex brain networks: graph theoretical analysis of structural and functional systems. Nat Rev Neurosci (2009) 10:186-98. doi:10.1038/nrn2575

27. Ogawa S, Tank DW, Menon R, Ellermann JM, Kim SG, Merkle H, et al. Intrinsic signal changes accompanying sensory stimulation: functional brain mapping with magnetic resonance imaging. Proc Natl Acad Sci U S A (1992) 89:5951-5. doi:10.1073/pnas.89.13.5951

28. Greicius MD, Krasnow B, Reiss AL, Menon V. Functional connectivity in the resting brain: a network analysis of the default mode hypothesis. Proc Natl Acad Sci U S A (2003) 100:253-8. doi:10.1073/pnas.0135058100

29. Shmuel A, Leopold DA. Neuronal correlates of spontaneous fluctuations in fMRI signals in monkey visual cortex: implications for functional connectivity at rest. Hum Brain Mapp (2008) 29:751-61. doi:10.1002/hbm.20580

30. Fahoum F, Zelmann R, Tyvaert L, Dubeau F, Gotman J. Epileptic discharges affect the default mode network - FMRI and intracerebral EEG evidence. PLoS One (2013) 8:e68038. doi:10.1371/journal.pone.0068038

31. Raichle ME, MacLeod AM, Snyder AZ, Powers WJ, Gusnard DA, Shulman GL. A default mode of brain function. Proc Natl Acad Sci U S A (2001) 98:676-82. doi:10.1073/pnas.98.2.676

32. Buckner RL, Andrews-Hanna JR, Schacter DL. The brain's default network: anatomy, function, and relevance to disease. Ann N Y Acad Sci (2008) 1124:1-38. doi:10.1196/annals.1440.011

33. Cavanna AE, Trimble MR. The precuneus: a review of its functional anatomy and behavioural correlates. Brain (2006) 129:564-83. doi:10.1093/brain/ awl004 
34. Biswal B, Yetkin FZ, Haughton VM, Hyde JS. Functional connectivity in the motor cortex of resting human brain using echo-planar MRI. Magn Reson Med (1995) 34:537-41. doi:10.1002/mrm.1910340409

35. McKeown MJ, Makeig S, Brown GG, Jung TP, Kindermann SS, Bell AJ, et al. Analysis of fMRI data by blind separation into independent spatial components. Hum Brain Mapp (1998) 6:160-88. doi:10.1002/(SICI)1097-0193(1998) 6:5/6<368::AID-HBM7>3.3.CO;2-5

36. Bellec P, Rosa-Neto P, Lyttelton OC, Benali H, Evans AC. Multi-level bootstrap analysis of stable clusters in resting-state fMRI. Neuroimage (2010) 51:1126-39. doi:10.1016/j.neuroimage.2010.02.082

37. Lemieux L, Daunizeau J, Walker MC. Concepts of connectivity and human epileptic activity. Front Syst Neurosci (2011) 5:12. doi:10.3389/fnsys.2011.00012

38. Biswal BB. Resting state fMRI: a personal history. Neuroimage (2012) 62:938-44. doi:10.1016/j.neuroimage.2012.01.090

39. De Vico Fallani F, Astolfi L, Cincotti F, Mattia D, Maglione AG, Vecchiato G, et al. Large-scale cortical networks estimated from scalp EEG signals during performance of goal-directed motor tasks. Conf Proc IEEE Eng Med Biol Soc (2010) 2010:1738-41. doi:10.1109/IEMBS.2010.5626710

40. De Pasquale F, Della Penna S, Snyder AZ, Lewis C, Mantini D, Marzetti L, et al. Temporal dynamics of spontaneous MEG activity in brain networks. Proc Natl Acad Sci U S A (2010) 107:6040-5. doi:10.1073/pnas.0913863107

41. Brookes MJ, Woolrich M, Luckhoo H, Price D, Hale JR, Stephenson MC, et al. Investigating the electrophysiological basis of resting state networks using magnetoencephalography. Proc Natl Acad Sci U S A (2011) 108:16783-8. doi:10.1073/pnas.1112685108

42. Cabral J, Kringelbach ML, Deco G. Exploring the network dynamics underlying brain activity during rest. Prog Neurobiol (2014) 114:102-31. doi:10.1016/ j.pneurobio.2013.12.005

43. Lehmann D. Topography of spontaneous alpha EEG fields in humans. Electroencephalogr Clin Neurophysiol (1971) 30:161-2.

44. Dierks T, Jelic V, Julin P, Maurer K, Wahlund LO, Almkvist O, et al. EEGmicrostates in mild memory impairment and Alzheimer's disease: possible association with disturbed information processing. J Neural Transm (1997) 104:483-95. doi:10.1007/BF01277666

45. Strelets V, Faber PL, Golikova J, Novototsky-Vlasov V, Koenig T, Gianotti LR, et al. Chronic schizophrenics with positive symptomatology have shortened EEG microstate durations. Clin Neurophysiol (2003) 114:2043-51. doi:10.1016/S1388-2457(03)00211-6

46. Koenig T, Prichep L, Lehmann D, Sosa PV, Braeker E, Kleinlogel H, et al. Millisecond by millisecond, year by year: normative EEG microstates and developmental stages. Neuroimage (2002) 16:41-8. doi:10.1006/nimg.2002. 1070

47. Lehmann D, Strik WK, Henggeler B, Koenig T, Koukkou M. Brain electric microstates and momentary conscious mind states as building blocks of spontaneous thinking: I. Visual imagery and abstract thoughts. Int J Psychophysiol (1998) 29:1-11.

48. Michel CM, Murray MM. Towards the utilization of EEG as a brain imaging tool. Neuroimage (2012) 61:371-85. doi:10.1016/j.neuroimage.2011.12.039

49. Britz J, Van De Ville D, Michel CM. BOLD correlates of EEG topography reveal rapid resting-state network dynamics. Neuroimage (2010) 52:1162-70. doi:10.1016/j.neuroimage.2010.02.052

50. Mantini D, Perrucci MG, Del Gratta C, Romani GL, Corbetta M. Electrophysiological signatures of resting state networks in the human brain. Proc Natl Acad Sci U S A (2007) 104:13170-5. doi:10.1073/pnas.0700668104

51. Van De Ville D, Britz J, Michel CM. EEG microstate sequences in healthy humans at rest reveal scale-free dynamics. Proc Natl Acad Sci U S A (2010) 107:18179-84. doi:10.1073/pnas.1007841107

52. Knowlton RC, Elgavish RA, Limdi N, Bartolucci A, Ojha B, Blount J, et al. Functional imaging: I. relative predictive value of intracranial electroencephalography. Ann Neurol (2008) 64:25-34. doi:10.1002/ana.21389

53. Knowlton RC, Razdan SN, Limdi N, Elgavish RA, Killen J, Blount J, et al. Effect of epilepsy magnetic source imaging on intracranial electrode placement. Ann Neurol (2009) 65:716-23. doi:10.1002/ana.21660

54. Brodbeck V, Spinelli L, Lascano AM, Wissmeier M, Vargas MI, Vulliemoz S, et al. Electroencephalographic source imaging: a prospective study of 152 operated epileptic patients. Brain (2011) 134:2887-97. doi:10.1093/brain/awr243
55. Megevand P, Spinelli L, Genetti M, Brodbeck V, Momjian S, Schaller K, et al. Electric source imaging of interictal activity accurately localises the seizure onset zone. J Neurol Neurosurg Psychiatry (2014) 85:38-43. doi:10.1136/jnnp2013-305515

56. Schoffelen JM, Gross J. Source connectivity analysis with MEG and EEG. Hum Brain Mapp (2009) 30:1857-65. doi:10.1002/hbm.20745

57. Plummer C, Harvey AS, Cook M. EEG source localization in focal epilepsy: where are we now? Epilepsia (2008) 49:201-18. doi:10.1111/j.1528-1167.2007. 01381.x

58. Kaiboriboon K, Luders HO, Hamaneh M, Turnbull J, Lhatoo SD. EEG source imaging in epilepsy - practicalities and pitfalls. Nat Rev Neurol (2012) 8:498-507. doi:10.1038/nrneurol.2012.150

59. Birot G, Spinelli L, Vulliemoz S, Megevand P, Brunet D, Seeck M, et al. Head model and electrical source imaging: a study of 38 epileptic patients. Neuroimage Clin (2014) 5:77-83. doi:10.1016/j.nicl.2014.06.005

60. Plummer C, Wagner M, Fuchs M, Harvey AS, Cook MJ. Dipole versus distributed EEG source localization for single versus averaged spikes in focal epilepsy. J Clin Neurophysiol (2010) 27:141-62. doi:10.1097/WNP.0b013e3181dd5004

61. Dai Y, Zhang W, Dickens DL, He B. Source connectivity analysis from MEG and its application to epilepsy source localization. Brain Topogr (2012) 25:157-66. doi:10.1007/s10548-011-0211-0

62. Jin SH, Jeong W, Chung CK. Information source in multiple MEG spike clusters can be identified by effective connectivity in focal cortical dysplasia. Epilepsy Res (2013) 105:118-24. doi:10.1016/j.eplepsyres.2013.01.011

63. Tanaka N, Peters JM, Prohl AK, Takaya S, Madsen JR, Bourgeois BF, et al. Clinical value of magnetoencephalographic spike propagation represented by spatiotemporal source analysis: correlation with surgical outcome. Epilepsy Res (2014) 108:280-8. doi:10.1016/j.eplepsyres.2013.11.006

64. Douw L, Van Dellen E, De Groot M, Heimans JJ, Klein M, Stam CJ, et al. Epilepsy is related to theta band brain connectivity and network topology in brain tumor patients. BMC Neurosci (2010) 11:103. doi:10.1186/1471-2202-11-103

65. Van Dellen E, Douw L, Hillebrand A, De Witt Hamer PC, Baayen JC, Heimans JJ, et al. Epilepsy surgery outcome and functional network alterations in longitudinal MEG: a minimum spanning tree analysis. Neuroimage (2014) 86:354-63. doi:10.1016/j.neuroimage.2013.10.010

66. Varotto G, Visani E, Canafoglia L, Franceschetti S, Avanzini G, Panzica F. Enhanced frontocentral EEG connectivity in photosensitive generalized epilepsies: a partial directed coherence study. Epilepsia (2012) 53:359-67. doi:10.1111/j.1528-1167.2011.03352.x

67. Gupta D, Ossenblok P, Van Luijtelaar G. Space-time network connectivity and cortical activations preceding spike wave discharges in human absence epilepsy: a MEG study. Med Biol Eng Comput (2011) 49:555-65. doi:10.1007/s11517011-0778-3

68. Malinowska U, Badier JM, Gavaret M, Bartolomei F, Chauvel P, Benar CG. Interictal networks in magnetoencephalography. Hum Brain Mapp (2014) 35:2789-805. doi:10.1002/hbm.22367

69. Kleen JK, Scott RC, Holmes GL, Roberts DW, Rundle MM, Testorf M, et al. Hippocampal interictal epileptiform activity disrupts cognition in humans. Neurology (2013) 81:18-24. doi:10.1212/WNL.0b013e318297ee50

70. Ives JR, Warach S, Schmitt F, Edelman RR, Schomer DL. Monitoring the patient's EEG during echo planar MRI. Electroencephalogr Clin Neurophysiol (1993) 87:417-20. doi:10.1016/0013-4694(93)90156-P

71. Gotman J, Kobayashi E, Bagshaw AP, Benar CG, Dubeau F. Combining EEG and fMRI: a multimodal tool for epilepsy research. J Magn Reson Imaging (2006) 23:906-20. doi:10.1002/jmri.20577

72. Van Houdt PJ, De Munck JC, Leijten FS, Huiskamp GJ, Colon AJ, Boon PA, et al. EEG-fMRI correlation patterns in the presurgical evaluation of focal epilepsy: a comparison with electrocorticographic data and surgical outcome measures. Neuroimage (2013) 75:238-48. doi:10.1016/j.neuroimage.2013.02.033

73. Pittau F, Grouiller F, Spinelli L, Seeck M, Michel CM, Vulliemoz S. The role of functional neuroimaging in pre-surgical epilepsy evaluation. Front Neurol (2014) 5:31. doi:10.3389/fneur.2014.00031

74. Seeck M, Lazeyras F, Michel CM, Blanke O, Gericke CA, Ives J, et al. Noninvasive epileptic focus localization using EEG-triggered functional MRI and electromagnetic tomography. Electroencephalogr Clin Neurophysiol (1998) 106:508-12. doi:10.1016/S0013-4694(98)00017-0 
75. Benar CG, Gross DW, Wang Y, Petre V, Pike B, Dubeau F, et al. The BOLD response to interictal epileptiform discharges. Neuroimage (2002) 17:1182-92. doi:10.1006/nimg.2002.1164

76. Thornton R, Vulliemoz S, Rodionov R, Carmichael DW, Chaudhary UJ, Diehl B, et al. Epileptic networks in focal cortical dysplasia revealed using electroencephalography-functional magnetic resonance imaging. Ann Neurol (2011) 70:822-37. doi:10.1002/ana.22535

77. An D, Fahoum F, Hall J, Olivier A, Gotman J, Dubeau F. Electroencephalography/functional magnetic resonance imaging responses help predict surgical outcome in focal epilepsy. Epilepsia (2013) 54:2184-94. doi:10.1111/epi. 12434

78. Grouiller F, Thornton RC, Groening K, Spinelli L, Duncan JS, Schaller K, et al. With or without spikes: localization of focal epileptic activity by simultaneous electroencephalography and functional magnetic resonance imaging. Brain (2011) 134:2867-86. doi:10.1093/brain/awr156

79. Glover GH. Deconvolution of impulse response in event-related BOLD fMRI. Neuroimage (1999) 9:416-29. doi:10.1006/nimg.1998.0419

80. Bagshaw AP, Aghakhani Y, Benar CG, Kobayashi E, Hawco C, Dubeau F, et al. EEG-fMRI of focal epileptic spikes: analysis with multiple haemodynamic functions and comparison with gadolinium-enhanced MR angiograms. Hum Brain Mapp (2004) 22:179-92. doi:10.1002/hbm.20024

81. Hawco CS, Bagshaw AP, Lu Y, Dubeau F, Gotman J. BOLD changes occur prior to epileptic spikes seen on scalp EEG. Neuroimage (2007) 35:1450-8. doi:10.1016/j.neuroimage.2006.12.042

82. Grouiller F, Vercueil L, Krainik A, Segebarth C, Kahane P, David O. Characterization of the hemodynamic modes associated with interictal epileptic activity using a deformable model-based analysis of combined EEG and functional MRI recordings. Hum Brain Mapp (2010) 31:1157-73. doi:10.1002/ hbm.20925

83. Moeller F, Levan P, Muhle H, Stephani U, Dubeau F, Siniatchkin M, et al. Absence seizures: individual patterns revealed by EEG-fMRI. Epilepsia (2010) 51:2000-10. doi:10.1111/j.1528-1167.2010.02698.x

84. Vaudano AE, Avanzini P, Tassi L, Ruggieri A, Cantalupo G, Benuzzi F, et al. Causality within the epileptic network: an EEG-fMRI study validated by intracranial EEG. Front Neurol (2013) 4:185. doi:10.3389/fneur.2013.00185

85. Groening K, Brodbeck V, Moeller F, Wolff S, Van Baalen A, Michel CM, et al. Combination of EEG-fMRI and EEG source analysis improves interpretation of spike-associated activation networks in paediatric pharmacoresistant focal epilepsies. Neuroimage (2009) 46:827-33. doi:10.1016/j.neuroimage. 2009.02.026

86. Vulliemoz S, Thornton R, Rodionov R, Carmichael DW, Guye M, Lhatoo $\mathrm{S}$, et al. The spatio-temporal mapping of epileptic networks: combination of EEG-fMRI and EEG source imaging. Neuroimage (2009) 46:834-43. doi:10.1016/j.neuroimage.2009.01.070

87. Laufs H, Richardson MP, Salek-Haddadi A, Vollmar C, Duncan JS, Gale $\mathrm{K}$, et al. Converging PET and fMRI evidence for a common area involved in human focal epilepsies. Neurology (2011) 77:904-10. doi:10.1212/WNL. 0b013e31822c90f2

88. Flanagan D, Badawy RA, Jackson GD. EEG-fMRI in focal epilepsy: local activation and regional networks. Clin Neurophysiol (2014) 125:21-31. doi:10.1016/ j.clinph.2013.06.182

89. Vaudano AE, Carmichael DW, Salek-Haddadi A, Rampp S, Stefan H, Lemieux $\mathrm{L}$, et al. Networks involved in seizure initiation. A reading epilepsy case studied with EEG-fMRI and MEG. Neurology (2012) 79:249-53. doi:10.1212/WNL. 0b013e31825fdf3a

90. Piredda S, Gale K. A crucial epileptogenic site in the deep prepiriform cortex. Nature (1985) 317:623-5. doi:10.1038/317623a0

91. Racine RJ, Mosher M, Kairiss EW. The role of the pyriform cortex in the generation of interictal spikes in the kindled preparation. Brain Res (1988) 454:251-63. doi:10.1016/0006-8993(88)90825-6

92. Loscher W, Ebert U. The role of the piriform cortex in kindling. Prog Neurobiol (1996) 50:427-81. doi:10.1016/S0301-0082(96)00036-6

93. Centeno M, Vollmar C, Stretton J, Symms MR, Thompson PJ, Richardson $\mathrm{MP}$, et al. Structural changes in the temporal lobe and piriform cortex in frontal lobe epilepsy. Epilepsy Res (2014) 108:978-81. doi:10.1016/j.eplepsyres. 2014.03.001

94. Hamandi K, Powell HW, Laufs H, Symms MR, Barker GJ, Parker GJ, et al. Combined EEG-fMRI and tractography to visualise propagation of epileptic activity. J Neurol Neurosurg Psychiatry (2008) 79:594-7. doi:10.1136/jnnp.2007. 125401

95. Bhardwaj RD, Mahmoodabadi SZ, Otsubo H, Snead OC III, Rutka JT, Widjaja E. Diffusion tensor tractography detection of functional pathway for the spread of epileptiform activity between temporal lobe and Rolandic region. Childs Nerv Syst (2010) 26:185-90. doi:10.1007/s00381-0091017-1

96. Lascano AM, Lemkaddem A, Granziera C, Korff CM, Boex C, Jenny B, et al. Tracking the source of cerebellar epilepsy: hemifacial seizures associated with cerebellar cortical dysplasia. Epilepsy Res (2013) 105:245-9. doi:10.1016/j. eplepsyres.2012.12.010

97. Kleen JK, Scott RC, Holmes GL, Lenck-Santini PP. Hippocampal interictal spikes disrupt cognition in rats. Ann Neurol (2010) 67:250-7. doi:10.1002/ana 21896

98. Chaudhary UJ, Centeno M, Carmichael DW, Vollmar C, Rodionov R, Bonelli S, et al. Imaging the interaction: epileptic discharges, working memory, and behavior. Hum Brain Mapp (2013) 34:2910-7. doi:10.1002/hbm. 22115

99. Centeno M, Carmichael DW. Network connectivity in epilepsy: resting state fMRI and EEG-fMRI contributions. Front Neurol (2014) 5:93. doi:10.3389/ fneur.2014.00093

100. Spencer SS. Neural networks in human epilepsy: evidence of and implications for treatment. Epilepsia (2002) 43:219-27. doi:10.1046/j.1528-1157.2002. 26901.x

101. Voets NL, Adcock JE, Stacey R, Hart Y, Carpenter K, Matthews PM, et al. Functional and structural changes in the memory network associated with left temporal lobe epilepsy. Hum Brain Mapp (2009) 30:4070-81. doi:10.1002/ hbm. 20830

102. Bettus G, Bartolomei F, Confort-Gouny S, Guedj E, Chauvel P, Cozzone PJ, et al. Role of resting state functional connectivity MRI in presurgical investigation of mesial temporal lobe epilepsy. J Neurol Neurosurg Psychiatry (2010) 81:1147-54. doi:10.1136/jnnp.2009.191460

103. Pereira FR, Alessio A, Sercheli MS, Pedro T, Bilevicius E, Rondina JM, et al. Asymmetrical hippocampal connectivity in mesial temporal lobe epilepsy: evidence from resting state fMRI. BMC Neurosci (2010) 11:66. doi:10.1186/14712202-11-66

104. Bettus G, Guedj E, Joyeux F, Confort-Gouny S, Soulier E, Laguitton V, et al. Decreased basal fMRI functional connectivity in epileptogenic networks and contralateral compensatory mechanisms. Hum Brain Mapp (2009) 30:1580-91. doi:10.1002/hbm.20625

105. Addis DR, Moscovitch M, McAndrews MP. Consequences of hippocampal damage across the autobiographical memory network in left temporal lobe epilepsy. Brain (2007) 130:2327-42. doi:10.1093/brain/awm166

106. Powell HW, Richardson MP, Symms MR, Boulby PA, Thompson PJ, Duncan JS, et al. Reorganization of verbal and nonverbal memory in temporal lobe epilepsy due to unilateral hippocampal sclerosis. Epilepsia (2007) 48:1512-25. doi:10.1111/j.1528-1167.2007.01053.x

107. Morgan VL, Rogers BP, Sonmezturk HH, Gore JC, Abou-Khalil B. Cross hippocampal influence in mesial temporal lobe epilepsy measured with high temporal resolution functional magnetic resonance imaging. Epilepsia (2011) 52:1741-9. doi:10.1111/j.1528-1167.2011.03196.x

108. Bettus G, Ranjeva JP, Wendling F, Benar CG, Confort-Gouny S, Regis J, et al. Interictal functional connectivity of human epileptic networks assessed by intracerebral EEG and BOLD signal fluctuations. PLoS One (2011) 6:e20071 doi:10.1371/journal.pone.0020071

109. Pittau F, Grova C, Moeller F, Dubeau F, Gotman J. Patterns of altered functional connectivity in mesial temporal lobe epilepsy. Epilepsia (2012) 53:1013-23. doi:10.1111/j.1528-1167.2012.03464.x

110. Waites AB, Briellmann RS, Saling MM, Abbott DF, Jackson GD. Functional connectivity networks are disrupted in left temporal lobe epilepsy. Ann Neurol (2006) 59:335-43. doi:10.1002/ana.20733

111. Kobayashi E, Grova C, Tyvaert L, Dubeau F, Gotman J. Structures involved at the time of temporal lobe spikes revealed by interindividual group analysis of EEG/fMRI data. Epilepsia (2009) 50:2549-56. doi:10.1111/j.1528-1167.2009. 02180.x

112. Frings L, Schulze-Bonhage A, Spreer J, Wagner K. Remote effects of hippocampal damage on default network connectivity in the human brain. J Neurol (2009) 256:2021-9. doi:10.1007/s00415-009-5233-0 
113. Liao W, Zhang Z, Pan Z, Mantini D, Ding J, Duan X, et al. Altered functional connectivity and small-world in mesial temporal lobe epilepsy. PLoS One (2010) 5:e8525. doi:10.1371/journal.pone.0008525

114. Liao W, Zhang Z, Pan Z, Mantini D, Ding J, Duan X, et al. Default mode network abnormalities in mesial temporal lobe epilepsy: a study combining fMRI and DTI. Hum Brain Mapp (2011) 32:883-95. doi:10.1002/hbm. 21076

115. Zhang Z, Lu G, Zhong Y, Tan Q, Liao W, Wang Z, et al. Altered spontaneous neuronal activity of the default-mode network in mesial temporal lobe epilepsy. Brain Res (2010) 1323:152-60. doi:10.1016/j.brainres.2010.01.042

116. Haneef Z, Lenartowicz A, Yeh HJ, Engel J Jr, Stern JM. Effect of lateralized temporal lobe epilepsy on the default mode network. Epilepsy Behav (2012) 25:350-7. doi:10.1016/j.yebeh.2012.07.019

117. Morgan VL, Sonmezturk HH, Gore JC, Abou-Khalil B. Lateralization of temporal lobe epilepsy using resting functional magnetic resonance imaging connectivity of hippocampal networks. Epilepsia (2012) 53:1628-35. doi:10.1111/j.1528-1167.2012.03590.x

118. McCormick C, Quraan M, Cohn M, Valiante TA, McAndrews MP. Default mode network connectivity indicates episodic memory capacity in mesial temporal lobe epilepsy. Epilepsia (2013) 54:809-18. doi:10.1111/epi.12098

119. Andrews-Hanna JR, Reidler JS, Sepulcre J, Poulin R, Buckner RL. Functionalanatomic fractionation of the brain's default network. Neuron (2010) 65:550-62. doi:10.1016/j.neuron.2010.02.005

120. Damoiseaux JS, Rombouts SA, Barkhof F, Scheltens P, Stam CJ, Smith SM, et al. Consistent resting-state networks across healthy subjects. Proc Natl Acad Sci U $S$ A (2006) 103:13848-53. doi:10.1073/pnas.0601417103

121. Fransson P, Marrelec G. The precuneus/posterior cingulate cortex plays a pivotal role in the default mode network: evidence from a partial correlation network analysis. Neuroimage (2008) 42:1178-84. doi:10.1016/j.neuroimage. 2008.05.059

122. Yeo BT, Krienen FM, Chee MW, Buckner RL. Estimates of segregation and overlap of functional connectivity networks in the human cerebral cortex. Neuroimage (2013) 88C:212-27. doi:10.1016/j.neuroimage.2013.10.046

123. Heimer L, Alheid GF, De Olmos JS, Groenewegen HJ, Haber SN, Harlan RE, et al. The accumbens: beyond the core-shell dichotomy. J Neuropsychiatry Clin Neurosci (1997) 9:354-81.

124. Koob GF, Volkow ND. Neurocircuitry of addiction. Neuropsychopharmacology (2010) 35:217-38. doi:10.1038/npp.2009.110

125. Bunzeck N, Doeller CF, Dolan RJ, Duzel E. Contextual interaction between novelty and reward processing within the mesolimbic system. Hum Brain Mapp (2012) 33:1309-24. doi:10.1002/hbm.21288

126. Lieb JP, Dasheiff RM, Engel J Jr. Role of the frontal lobes in the propagation of mesial temporal lobe seizures. Epilepsia (1991) 32:822-37. doi:10.1111/j.15281157.1991.tb05539.x

127. Yadid G, Friedman A. Dynamics of the dopaminergic system as a key component to the understanding of depression. Prog Brain Res (2008) 172:265-86. doi:10.1016/S0079-6123(08)00913-8

128. Price JL, Drevets WC. Neurocircuitry of mood disorders. Neuropsychopharmacology (2010) 35:192-216. doi:10.1038/npp.2009.104

129. Chen S, Wu X, Lui S, Wu Q, Yao Z, Li Q, et al. Resting-state fMRI study of treatment-naive temporal lobe epilepsy patients with depressive symptoms. Neuroimage (2012) 60:299-304. doi:10.1016/j.neuroimage.2011.11.092

130. Butler T, Blackmon K, McDonald CR, Carlson C, Barr WB, Devinsky O, et al. Cortical thickness abnormalities associated with depressive symptoms in temporal lobe epilepsy. Epilepsy Behav (2012) 23:64-7. doi:10.1016/j.yebeh.2011. 10.001

131. Stretton J, Pope RA, Winston GP, Sidhu MK, Symms M, Duncan JS, et al. Temporal lobe epilepsy and affective disorders: the role of the subgenual anterior cingulate cortex. J Neurol Neurosurg Psychiatry (2014). doi:10.1136/jnnp2013-306966

132. Meletti S, Benuzzi F, Rubboli G, Cantalupo G, Stanzani Maserati M, Nichelli $\mathrm{P}$, et al. Impaired facial emotion recognition in early-onset right mesial temporal lobe epilepsy. Neurology (2003) 60:426-31. doi:10.1212/WNL. 60.3.426

133. Schacher M, Winkler R, Grunwald T, Kraemer G, Kurthen M, Reed V, et al. Mesial temporal lobe epilepsy impairs advanced social cognition. Epilepsia (2006) 47:2141-6. doi:10.1111/j.1528-1167.2006.00857.x
134. Hlobil U, Rathore C, Alexander A, Sarma S, Radhakrishnan K. Impaired facial emotion recognition in patients with mesial temporal lobe epilepsy associated with hippocampal sclerosis (MTLE-HS): side and age at onset matters. Epilepsy Res (2008) 80:150-7. doi:10.1016/j.eplepsyres.2008.03.018

135. Meletti S, Benuzzi F, Cantalupo G, Rubboli G, Tassinari CA, Nichelli P. Facial emotion recognition impairment in chronic temporal lobe epilepsy. Epilepsia (2009) 50:1547-59. doi:10.1111/j.1528-1167.2008.01978.x

136. Broicher SD, Frings L, Huppertz HJ, Grunwald T, Kurthen M, Kramer G, et al. Alterations in functional connectivity of the amygdala in unilateral mesial temporal lobe epilepsy. J Neurol (2012) 259:2546-54. doi:10.1007/s00415-0126533-3

137. Bonelli SB, Powell R, Yogarajah M, Thompson PJ, Symms MR, Koepp MJ, et al. Preoperative amygdala fMRI in temporal lobe epilepsy. Epilepsia (2009) 50:217-27. doi:10.1111/j.1528-1167.2008.01739.x

138. Cataldi M, Avoli M, De Villers-Sidani E. Resting state networks in temporal lobe epilepsy. Epilepsia (2013) 54:2048-59. doi:10.1111/epi.12400

139. Negishi M, Martuzzi R, Novotny EJ, Spencer DD, Constable RT. Functional MRI connectivity as a predictor of the surgical outcome of epilepsy. Epilepsia (2011) 52:1733-40. doi:10.1111/j.1528-1167.2011.03191.x

140. Luo C, An D, Yao D, Gotman J. Patient-specific connectivity pattern of epileptic network in frontal lobe epilepsy. Neuroimage Clin (2014) 4:668-75. doi:10.1016/j.nicl.2014.04.006

141. Centeno M, Vollmar C, O’Muircheartaigh J, Stretton J, Bonelli SB, Symms MR, et al. Memory in frontal lobe epilepsy: an fMRI study. Epilepsia (2012) 53:1756-64. doi:10.1111/j.1528-1167.2012.03570.x

142. Meeren H, Van Luijtelaar G, Da Silva F, Coenen A. Evolving concepts on the pathophysiology of absence seizures: the cortical focus theory. Arch Neurol (2005) 62:371-6. doi:10.1001/archneur.62.3.371

143. Blumenfeld H. Cellular and network mechanisms of spike-wave seizures. Epilepsia (2005) 46(Suppl 9):21-33. doi:10.1111/j.1528-1167.2005.00311.x

144. Gloor P. Generalized cortico-reticular epilepsies. Some considerations on the pathophysiology of generalized bilaterally synchronous spike and wave discharge. Epilepsia (1968) 9:249-63. doi:10.1111/j.1528-1157.1968. tb04624.x

145. Meeren HK, Pijn JP, Van Luijtelaar EL, Coenen AM, Da Silva FH. Cortical focus drives widespread corticothalamic networks during spontaneous absence seizures in rats. J Neurosci (2002) 22:1480-95.

146. Manning JP, Richards DA, Leresche N, Crunelli V, Bowery NG. Cortical-area specific block of genetically determined absence seizures by ethosuximide. $\mathrm{Neu}$ roscience (2004) 123:5-9. doi:10.1016/j.neuroscience.2003.09.026

147. Polack PO, Guillemain I, Hu E, Deransart C, Depaulis A, Charpier S. Deep layer somatosensory cortical neurons initiate spike-and-wave discharges in a genetic model of absence seizures. J Neurosci (2007) 27:6590-9. doi:10.1523/ JNEUROSCI.0753-07.2007

148. Archer JS, Abbott DF, Waites AB, Jackson GD. fMRI "deactivation" of the posterior cingulate during generalized spike and wave. Neuroimage (2003) 20:1915-22. doi:10.1016/S1053-8119(03)00294-5

149. Aghakhani Y, Bagshaw AP, Benar CG, Hawco C, Andermann F, Dubeau F, et al. fMRI activation during spike and wave discharges in idiopathic generalized epilepsy. Brain (2004) 127:1127-44. doi:10.1093/brain/awh136

150. Masterton RA, Carney PW, Abbott DF, Jackson GD. Absence epilepsy subnetworks revealed by event-related independent components analysis of functional magnetic resonance imaging. Epilepsia (2013) 54:801-8. doi:10.1111/ epi. 12163

151. Salek-Haddadi A, Lemieux L, Merschhemke M, Friston KJ, Duncan JS, Fish DR. Functional magnetic resonance imaging of human absence seizures. Ann Neurol (2003) 53:663-7. doi:10.1002/ana.10586

152. Labate A, Briellmann RS, Abbott DF, Waites AB, Jackson GD. Typical childhood absence seizures are associated with thalamic activation. Epileptic Disord (2005) 7:373-7.

153. Laufs H, Lengler U, Hamandi K, Kleinschmidt A, Krakow K. Linking generalized spike-and-wave discharges and resting state brain activity by using EEG/fMRI in a patient with absence seizures. Epilepsia (2006) 47:444-8. doi:10.1111/j.1528-1167.2006.00443.x

154. Moeller F, Siebner HR, Wolff S, Muhle H, Granert O, Jansen O, et al. Simultaneous EEG-fMRI in drug-naive children with newly diagnosed absence epilepsy. Epilepsia (2008) 49:1510-9. doi:10.1111/j.1528-1167.2008.01626.x 
155. Hamandi K, Salek-Haddadi A, Laufs H, Liston A, Friston K, Fish DR, et al. EEG-fMRI of idiopathic and secondarily generalized epilepsies. Neuroimage (2006) 31:1700-10. doi:10.1016/j.neuroimage.2006.02.016

156. Child ND, Benarroch EE. Anterior nucleus of the thalamus: functional organization and clinical implications. Neurology (2013) 81:1869-76. doi:10.1212/ 01.wnl.0000436078.95856.56

157. Carney PW, Masterton RA, Harvey AS, Scheffer IE, Berkovic SF, Jackson GD. The core network in absence epilepsy. Differences in cortical and thalamic BOLD response. Neurology (2010) 75:904-11. doi:10.1212/WNL. 0b013e3181f11c06

158. Westmijse I, Ossenblok P, Gunning B, Van Luijtelaar G. Onset and propagation of spike and slow wave discharges in human absence epilepsy: a MEG study. Epilepsia (2009) 50:2538-48. doi:10.1111/j.1528-1167.2009.02162.x

159. Roche-Labarbe N, Zaaimi B, Berquin P, Nehlig A, Grebe R, Wallois F. NIRSmeasured oxy- and deoxyhemoglobin changes associated with EEG spike-andwave discharges in children. Epilepsia (2008) 49:1871-80. doi:10.1111/j.15281167.2008.01711.x

160. Seneviratne U, Cook M, D’Souza W. Focal abnormalities in idiopathic generalized epilepsy: a critical review of the literature. Epilepsia (2014) 55:1157-69. doi:10.1111/epi.12688

161. Tyvaert L, Chassagnon S, Sadikot A, Levan P, Dubeau F, Gotman J. Thalamic nuclei activity in idiopathic generalized epilepsy: an EEG-fMRI study. Neurology (2009) 73:2018-22. doi:10.1212/WNL.0b013e3181c55d02

162. Wang Z, Lu G, Zhang Z, Zhong Y, Jiao Q, Tan Q, et al. Altered resting state networks in epileptic patients with generalized tonic-clonic seizures. Brain Res (2011) 1374:134-41. doi:10.1016/j.brainres.2010.12.034

163. McGill ML, Devinsky O, Kelly C, Milham M, Castellanos FX, Quinn BT, et al. Default mode network abnormalities in idiopathic generalized epilepsy. Epilepsy Behav (2012) 23:353-9. doi:10.1016/j.yebeh.2012.01.013

164. Zhang Z, Liao W, Chen H, Mantini D, Ding JR, Xu Q, et al. Altered functionalstructural coupling of large-scale brain networks in idiopathic generalized epilepsy. Brain (2011) 134:2912-28. doi:10.1093/brain/awr223

165. Maneshi M, Moeller F, Fahoum F, Gotman J, Grova C. Resting-state connectivity of the sustained attention network correlates with disease duration in idiopathic generalized epilepsy. PLoS One (2012) 7:e50359. doi:10.1371/journal. pone.0050359

166. Kay BP, Difrancesco MW, Privitera MD, Gotman J, Holland SK, Szaflarski JP. Reduced default mode network connectivity in treatment-resistant idiopathic generalized epilepsy. Epilepsia (2013) 54:461-70. doi:10.1111/epi. 12057

167. Kim JB, Suh SI, Seo WK, Oh K, Koh SB, Kim JH. Altered thalamocortical functional connectivity in idiopathic generalized epilepsy. Epilepsia (2014) 55:592-600. doi:10.1111/epi.12580

168. Vollmar C, O’Muircheartaigh J, Barker GJ, Symms MR, Thompson P, Kumari $\mathrm{V}$, et al. Motor system hyperconnectivity in juvenile myoclonic epilepsy: a cognitive functional magnetic resonance imaging study. Brain (2011) 134:1710-9. doi:10.1093/brain/awr098

169. Vulliemoz S, Vollmar C, Koepp MJ, Yogarajah M, O’Muircheartaigh J, Carmichael DW, et al. Connectivity of the supplementary motor area in juvenile myoclonic epilepsy and frontal lobe epilepsy. Epilepsia (2011) 52:507-14 doi:10.1111/j.1528-1167.2010.02770.x

170. Vollmar C, O’Muircheartaigh J, Symms MR, Barker GJ, Thompson P, Kumari V, et al. Altered microstructural connectivity in juvenile myoclonic epilepsy: the missing link. Neurology (2012) 78:1555-9. doi:10.1212/WNL. 0b013e3182563b44

171. Wandschneider B, Centeno M, Vollmar C, Stretton J, O’Muircheartaigh J, Thompson PJ, et al. Risk-taking behavior in juvenile myoclonic epilepsy. Epilepsia (2013) 54:2158-65. doi:10.1111/epi.12413

172. Moeller F, Stephani U, Siniatchkin M. Simultaneous EEG and fMRI recordings (EEG-fMRI) in children with epilepsy. Epilepsia (2013) 54:971-82. doi:10.1111/epi.12197

173. Siniatchkin M, Coropceanu D, Moeller F, Boor R, Stephani U. EEG-fMRI reveals activation of brainstem and thalamus in patients with LennoxGastaut syndrome. Epilepsia (2011) 52:766-74. doi:10.1111/j.1528-1167.2010. 02948.x

174. Pillay N, Archer JS, Badawy RA, Flanagan DF, Berkovic SF, Jackson G. Networks underlying paroxysmal fast activity and slow spike and wave in Lennox-Gastaut syndrome. Neurology (2013) 81:665-73. doi:10.1212/WNL.0b013e3182a08f6a
175. Archer JS, Warren AE, Stagnitti MR, Masterton RA, Abbott DF, Jackson GD. Lennox-Gastaut syndrome and phenotype: secondary network epilepsies. Epilepsia (2014) 55:1245-54. doi:10.1111/epi.12682

176. Moeller F, Groening K, Moehring J, Muhle H, Wolff S, Jansen O, et al. EEG-fMRI in myoclonic astatic epilepsy (Doose syndrome). Neurology (2014) 82:1508-13. doi:10.1212/WNL.0000000000000359

177. Archer JS, Briellman RS, Abbott DF, Syngeniotis A, Wellard RM, Jackson GD. Benign epilepsy with centro-temporal spikes: spike triggered fMRI shows somato-sensory cortex activity. Epilepsia (2003) 44:200-4. doi:10.1046/j.15281157.2003.02502.x

178. Boor S, Vucurevic G, Pfleiderer C, Stoeter P, Kutschke G, Boor R. EEG-related functional MRI in benign childhood epilepsy with centrotemporal spikes. Epilepsia (2003) 44:688-92. doi:10.1046/j.1528-1157.2003.27802.x

179. Lengler U, Kafadar I, Neubauer BA, Krakow K. fMRI correlates of interictal epileptic activity in patients with idiopathic benign focal epilepsy of childhood. A simultaneous EEG-functional MRI study. Epilepsy Res (2007) 75:29-38. doi:10.1016/j.eplepsyres.2007.03.016

180. Masterton RA, Harvey AS, Archer JS, Lillywhite LM, Abbott DF, Scheffer IE, et al. Focal epileptiform spikes do not show a canonical BOLD response in patients with benign rolandic epilepsy (BECTS). Neuroimage (2010) 51:252-60. doi:10.1016/j.neuroimage.2010.01.109

181. Siniatchkin M, Groening K, Moehring J, Moeller F, Boor R, Brodbeck V, et al. Neuronal networks in children with continuous spikes and waves during slow sleep. Brain (2010) 133:2798-813. doi:10.1093/brain/awq183

182. Mirandola L, Cantalupo G, Vaudano AE, Avanzini P, Ruggieri A, Pisani F, et al. Centrotemporal spikes during NREM sleep: the promoting action of thalamus revealed by simultaneous EEG and fMRI coregistration. Epilepsy Behav Case Rep (2013) 1:106-9. doi:10.1016/j.ebcr.2013.06.005

183. Moeller F, Moehring J, Ick I, Steinmann E, Wolff S, Jansen O, et al. EEG-fMRI in atypical benign partial epilepsy. Epilepsia (2013) 54:e103-8. doi:10.1111/epi. 12243

184. Vaudano AE, Ruggieri A, Vignoli A, Avanzini P, Benuzzi F, Gessaroli G, et al. Epilepsy-related brain networks in ring chromosome 20 syndrome: an EEGfMRI study. Epilepsia (2014) 55:403-13. doi:10.1111/epi.12539

185. Bartolomei F, Chauvel P, Wendling F. Epileptogenicity of brain structures in human temporal lobe epilepsy: a quantified study from intracerebral EEG. Brain (2008) 131:1818-30. doi:10.1093/brain/awn111

186. Bartolomei F, Cosandier-Rimele D, McGonigal A, Aubert S, Regis J, Gavaret $\mathrm{M}$, et al. From mesial temporal lobe to temporoperisylvian seizures: a quantified study of temporal lobe seizure networks. Epilepsia (2010) 51:2147-58. doi:10.1111/j.1528-1167.2010.02690.x

187. Arthuis M, Valton L, Regis J, Chauvel P, Wendling F, Naccache L, et al. Impaired consciousness during temporal lobe seizures is related to increased longdistance cortical-subcortical synchronization. Brain (2009) 132:2091-101. doi:10.1093/brain/awp086

188. Lambert I, Arthuis M, McGonigal A, Wendling F, Bartolomei F. Alteration of global workspace during loss of consciousness: a study of parietal seizures. Epilepsia (2012) 53:2104-10. doi:10.1111/j.1528-1167.2012.03690.x

189. Bartolomei F, McGonigal A, Naccache L. Alteration of consciousness in focal epilepsy: the global workspace alteration theory. Epilepsy Behav (2014) 30:17-23. doi:10.1016/j.yebeh.2013.09.012

190. Blumenfeld H, McNally KA, Vanderhill SD, Paige AL, Chung R, Davis K, et al. Positive and negative network correlations in temporal lobe epilepsy. Cereb Cortex (2004) 14:892-902. doi:10.1093/cercor/bhh048

191. Englot DJ, Yang L, Hamid H, Danielson N, Bai X, Marfeo A, et al. Impaired consciousness in temporal lobe seizures: role of cortical slow activity. Brain (2010) 133:3764-77. doi:10.1093/brain/awq316

192. Englot DJ, Modi B, Mishra AM, Desalvo M, Hyder F, Blumenfeld H. Cortical deactivation induced by subcortical network dysfunction in limbic seizures. J Neurosci (2009) 29:13006-18. doi:10.1523/JNEUROSCI.3846-09.2009

193. Blumenfeld H. Impaired consciousness in epilepsy. Lancet Neurol (2012) 11:814-26. doi:10.1016/S1474-4422(12)70188-6

194. Rubinov M, Sporns O. Complex network measures of brain connectivity: uses and interpretations. Neuroimage (2010) 52:1059-69. doi:10.1016/j. neuroimage.2009.10.003

195. Wilke C, Worrell G, He B. Graph analysis of epileptogenic networks in human partial epilepsy. Epilepsia (2011) 52:84-93. doi:10.1111/j.1528-1167. 2010.02785.x 
196. Van Mierlo P, Carrette E, Hallez H, Raedt R, Meurs A, Vandenberghe S, et al. Ictal-onset localization through connectivity analysis of intracranial EEG signals in patients with refractory epilepsy. Epilepsia (2013) 54:1409-18. doi:10.1111/epi.12206

197. Panzica F, Varotto G, Rotondi F, Spreafico R, Franceschetti S. Identification of the epileptogenic zone from stereo-EEG signals: a connectivity-graph theory approach. Front Neurol (2013) 4:175. doi:10.3389/fneur.2013.00175

198. Vulliemoz S, Carmichael DW, Rosenkranz K, Diehl B, Rodionov R, Walker $\mathrm{MC}$, et al. Simultaneous intracranial EEG and $\mathrm{PMRI}$ of interictal epileptic discharges in humans. Neuroimage (2011) 54:182-90. doi:10.1016/j.neuroimage. 2010.08.004

199. Carmichael DW, Vulliemoz S, Rodionov R, Thornton JS, McEvoy AW, Lemieux L. Simultaneous intracranial EEG-fMRI in humans: protocol considerations and data quality. Neuroimage (2012) 63:301-9. doi:10.1016/j.neuroimage.2012. 05.056

200. Schevon CA, Weiss SA, McKhann G Jr, Goodman RR, Yuste R, Emerson RG, et al. Evidence of an inhibitory restraint of seizure activity in humans. Nat Commun (2012) 3:1060. doi:10.1038/ncomms2056

201. Weiss SA, Banks GP, McKhann GM Jr, Goodman RR, Emerson RG, Trevelyan AJ, et al. Ictal high frequency oscillations distinguish two types of seizure territories in humans. Brain (2013) 136:3796-808. doi:10.1093/brain/ awt276

202. Penfield W, Boldrey E. Somatic motor and sensory representation in the cerebral cortex of man as studied by electrical stimulation. Brain (1937) 60:389-443. doi:10.1093/brain/60.4.389

203. Hamberger MJ. Cortical language mapping in epilepsy: a critical review. Neuropsychol Rev (2007) 17:477-89. doi:10.1007/s11065-007-9046-6

204. Selimbeyoglu A, Parvizi J. Electrical stimulation of the human brain: perceptual and behavioral phenomena reported in the old and new literature. Front Hum Neurosci (2010) 4:46. doi:10.3389/fnhum.2010.00046

205. Megevand P, Groppe DM, Goldfinger MS, Hwang ST, Kingsley PB, Davidesco I, et al. Seeing scenes: topographic visual hallucinations evoked by direct electrical stimulation of the parahippocampal place area. J Neurosci (2014) 34:5399-405. doi:10.1523/JNEUROSCI.5202-13.2014

206. Parvizi J, Rangarajan V, Shirer WR, Desai N, Greicius MD. The will to persevere induced by electrical stimulation of the human cingulate gyrus. Neuron (2013) 80:1359-67. doi:10.1016/j.neuron.2013.10.057

207. Matsumoto R, Nair DR, Lapresto E, Najm I, Bingaman W, Shibasaki H, et al. Functional connectivity in the human language system: a cortico-cortical evoked potential study. Brain (2004) 127:2316-30. doi:10.1093/brain/awh246

208. Conner CR, Ellmore TM, Disano MA, Pieters TA, Potter AW, Tandon N. Anatomic and electro-physiologic connectivity of the language system: a combined DTI-CCEP study. Comput Biol Med (2011) 41:1100-9. doi:10.1016/j. compbiomed.2011.07.008

209. David O, Bastin J, Chabardes S, Minotti L, Kahane P. Studying network mechanisms using intracranial stimulation in epileptic patients. Front Syst Neurosci (2010) 4:148. doi:10.3389/fnsys.2010.00148

210. Wilson CL, Isokawa M, Babb TL, Crandall PH. Functional connections in the human temporal lobe. I. analysis of limbic system pathways using neuronal responses evoked by electrical stimulation. Exp Brain Res (1990) 82: 279-92.

211. Lacruz ME, Garcia Seoane JJ, Valentin A, Selway R, Alarcon G. Frontal and temporal functional connections of the living human brain. Eur J Neurosci (2007) 26:1357-70. doi:10.1111/j.1460-9568.2007.05730.x

212. Gloor P, Salanova V, Olivier A, Quesney LF. The human dorsal hippocampal commissure. An anatomically identifiable and functional pathway. Brain (1993) 116(Pt 5):1249-73. doi:10.1093/brain/116.5.1249

213. David O, Job AS, De Palma L, Hoffmann D, Minotti L, Kahane P. Probabilistic functional tractography of the human cortex. Neuroimage (2013) 80:307-17. doi:10.1016/j.neuroimage.2013.05.075

214. Iwasaki M, Enatsu R, Matsumoto R, Novak E, Thankappen B, Piao Z, et al. Accentuated cortico-cortical evoked potentials in neocortical epilepsy in areas of ictal onset. Epileptic Disord (2010) 12:292-302. doi:10.1684/epd.2010. 0334

215. Valentin A, Anderson M, Alarcon G, Seoane JJ, Selway R, Binnie CD, et al. Responses to single pulse electrical stimulation identify epileptogenesis in the human brain in vivo. Brain (2002) 125:1709-18. doi:10.1093/brain/ awf187
216. Enatsu R, Jin K, Elwan S, Kubota Y, Piao Z, O'Connor T, et al. Correlations between ictal propagation and response to electrical cortical stimulation: a cortico-cortical evoked potential study. Epilepsy Res (2012) 101:76-87. doi:10.1016/j.eplepsyres.2012.03.004

217. Berenyi A, Belluscio M, Mao D, Buzsaki G. Closed-loop control of epilepsy by transcranial electrical stimulation. Science (2012) 337:735-7. doi:10.1126/ science. 1223154

218. Buckmaster PS. Laboratory animal models of temporal lobe epilepsy. Comp Med (2004) 54:473-85.

219. Mishra AM, Bai H, Gribizis A, Blumenfeld H. Neuroimaging biomarkers of epileptogenesis. Neurosci Lett (2011) 497:194-204. doi:10.1016/j.neulet.2011. 01.076

220. Coppola A, Moshe SL. Animal models. Handb Clin Neurol (2012) 107:63-98. doi:10.1016/B978-0-444-52898-8.00004-5

221. Guillemain I, Kahane P, Depaulis A. Animal models to study aetiopathology of epilepsy: what are the features to model? Epileptic Disord (2012) 14:217-25 doi:10.1684/epd.2012.0528

222. Galanopoulou AS. Basic mechanisms of catastrophic epilepsy - overview from animal models. Brain Dev (2013) 35:748-56. doi:10.1016/j.braindev. 2012.12.005

223. Cossart R, Dinocourt C, Hirsch JC, Merchan-Perez A, De Felipe J, Ben-Ari Y, et al. Dendritic but not somatic GABAergic inhibition is decreased in experimental epilepsy. Nat Neurosci (2001) 4:52-62. doi:10.1038/82900

224. Soussi R, Boulland JL, Bassot E, Bras H, Coulon P, Chaudhry FA, et al. Reorganization of supramammillary-hippocampal pathways in the rat pilocarpine model of temporal lobe epilepsy: evidence for axon terminal sprouting. Brain Struct Funct (2014). doi:10.1007/s00429-014-0800-2

225. Mishra AM, Ellens DJ, Schridde U, Motelow JE, Purcaro MJ, Desalvo MN, et al. Where fMRI and electrophysiology agree to disagree: corticothalamic and striatal activity patterns in the WAG/Rij rat. J Neurosci (2011) 31:15053-64. doi:10.1523/JNEUROSCI.0101-11.2011

226. Elms J, Powell KL, Van Raay L, Dedeurwaerdere S, O’Brien TJ, Morris MJ. Long-term valproate treatment increases brain neuropeptide $\mathrm{Y}$ expression and decreases seizure expression in a genetic rat model of absence epilepsy. PLoS One (2013) 8:e73505. doi:10.1371/journal.pone.0073505

227. Carcak N, Zheng T, Ali I, Abdullah A, French C, Powell KL, et al. The effect of amygdala kindling on neuronal firing patterns in the lateral thalamus in the GAERS model of absence epilepsy. Epilepsia (2014) 55:654-65. doi:10.1111/ epi. 12592

228. Bouilleret V, Ridoux V, Depaulis A, Marescaux C, Nehlig A, La Salle G. Recurrent seizures and hippocampal sclerosis following intrahippocampal kainate injection in adult mice: electroencephalography, histopathology and synaptic reorganization similar to mesial temporal lobe epilepsy. Neuroscience (1999) 89:717-29. doi:10.1016/S0306-4522(98)00401-1

229. Leite JP, Garcia-Cairasco N, Cavalheiro EA. New insights from the use of pilocarpine and kainate models. Epilepsy Res (2002) 50:93-103. doi:10.1016/ S0920-1211(02)00072-4

230. Riban V, Bouilleret V, Pham-Le BT, Fritschy JM, Marescaux C, Depaulis A. Evolution of hippocampal epileptic activity during the development of hippocampal sclerosis in a mouse model of temporal lobe epilepsy. Neuroscience (2002) 112:101-11. doi:10.1016/S0306-4522(02)00064-7

231. Marchi N, Oby E, Batra A, Uva L, De Curtis M, Hernandez N, et al. In vivo and in vitro effects of pilocarpine: relevance to ictogenesis. Epilepsia (2007) 48:1934-46. doi:10.1111/j.1528-1167.2007.01185.x

232. Curia G, Longo D, Biagini G, Jones RS, Avoli M. The pilocarpine model of temporal lobe epilepsy. J Neurosci Methods (2008) 172:143-57. doi:10.1016/j. jneumeth.2008.04.019

233. Deprez F, Zattoni M, Mura ML, Frei K, Fritschy JM. Adoptive transfer of T lymphocytes in immunodeficient mice influences epileptogenesis and neurodegeneration in a model of temporal lobe epilepsy. Neurobiol Dis (2011) 44:174-84. doi:10.1016/j.nbd.2011.06.011

234. Zattoni M, Mura ML, Deprez F, Schwendener RA, Engelhardt B, Frei K, et al. Brain infiltration of leukocytes contributes to the pathophysiology of temporal lobe epilepsy. J Neurosci (2011) 31:4037-50. doi:10.1523/JNEUROSCI.621010.2011

235. Lothman EW, Hatlelid JM, Zorumski CF, Conry JA, Moon PF, Perlin JB. Kindling with rapidly recurring hippocampal seizures. Brain Res (1985) 360:83-91. doi:10.1016/0006-8993(85)91223-5 
236. Morales JC, Alvarez-Ferradas C, Roncagliolo M, Fuenzalida M, Wellmann $\mathrm{M}$, Nualart FJ, et al. A new rapid kindling variant for induction of cortical epileptogenesis in freely moving rats. Front Cell Neurosci (2014) 8:200. doi:10.3389/fncel.2014.00200

237. Kowski AB, Kanaan H, Schmitt FC, Holtkamp M. Deep hypothermia terminates status epilepticus - an experimental study. Brain Res (2012) 1446:119-26. doi:10.1016/j.brainres.2012.01.022

238. Reddy DS, Kuruba R. Experimental models of status epilepticus and neuronal injury for evaluation of therapeutic interventions. Int J Mol Sci (2013) 14:18284-318. doi:10.3390/ijms140918284

239. Wang CH, Hung CP, Chen MT, Shih YH, Lin YY. Hippocampal desynchronization of functional connectivity prior to the onset of status epilepticus in pilocarpine-treated rats. PLoS One (2012) 7:e39763. doi:10.1371/journal.pone. 0039763

240. Gong XW, Li JB, Lu QC, Liang PJ, Zhang PM. Effective connectivity of hippocampal neural network and its alteration in Mg2+-free epilepsy model. PLoS One (2014) 9:e92961. doi:10.1371/journal.pone.0092961

241. Cymerblit-Sabba A, Schiller Y. Network dynamics during development of pharmacologically induced epileptic seizures in rats in vivo. J Neurosci (2010) 30:1619-30. doi:10.1523/JNEUROSCI.5078-09.2010

242. Englot DJ, Mishra AM, Mansuripur PK, Herman P, Hyder F, Blumenfeld H. Remote effects of focal hippocampal seizures on the rat neocortex. J Neurosci (2008) 28:9066-81. doi:10.1523/JNEUROSCI.2014-08.2008

243. Megevand P, Quairiaux C, Lascano AM, Kiss JZ, Michel CM. A mouse model for studying large-scale neuronal networks using EEG mapping techniques. Neuroimage (2008) 42:591-602. doi:10.1016/j.neuroimage.2008. 05.016

244. Megevand P, Troncoso E, Quairiaux C, Muller D, Michel CM, Kiss JZ. Long-term plasticity in mouse sensorimotor circuits after rhythmic whisker stimulation. J Neurosci (2009) 29:5326-35. doi:10.1523/JNEUROSCI.5965-08. 2009

245. Quairiaux C, Sizonenko SV, Megevand P, Michel CM, Kiss JZ. Functional deficit and recovery of developing sensorimotor networks following neonatal hypoxic-ischemic injury in the rat. Cereb Cortex (2010) 20:2080-91. doi:10.1093/cercor/bhp281

246. Quairiaux C, Megevand P, Kiss JZ, Michel CM. Functional development of large-scale sensorimotor cortical networks in the brain. J Neurosci (2011) 31:9574-84. doi:10.1523/JNEUROSCI.5995-10.2011

247. Toyoda I, Bower MR, Leyva F, Buckmaster PS. Early activation of ventral hippocampus and subiculum during spontaneous seizures in a rat model of temporal lobe epilepsy. J Neurosci (2013) 33:11100-15. doi:10.1523/JNEUROSCI. 0472-13.2013

248. Berenyi A, Somogyvari Z, Nagy AJ, Roux L, Long JD, Fujisawa S, et al. Large-scale, high-density (up to 512 channels) recording of local circuits in behaving animals. J Neurophysiol (2014) 111:1132-49. doi:10.1152/jn.00785. 2013

249. Mishra AM, Bai X, Sanganahalli BG, Waxman SG, Shatillo O, Grohn O, et al. Decreased resting functional connectivity after traumatic brain injury in the rat. PLoS One (2014) 9:e95280. doi:10.1371/journal.pone.0095280

250. Mishra AM, Bai X, Motelow JE, Desalvo MN, Danielson N, Sanganahalli $\mathrm{BG}$, et al. Increased resting functional connectivity in spike-wave epilepsy in WAG/Rij rats. Epilepsia (2013) 54:1214-22. doi:10.1111/epi.12227

251. Choi H, Kim YK, Kang H, Lee H, Im HJ, Hwang DW, et al. Abnormal metabolic connectivity in the pilocarpine-induced epilepsy rat model: a multiscale network analysis based on persistent homology. Neuroimage (2014) 99C:226-36. doi:10.1016/j.neuroimage.2014.05.039

252. Xia Y, Lai Y, Lei L, Liu Y, Yao D. Left hemisphere predominance of pilocarpineinduced rat epileptiform discharges. J Neuroeng Rehabil (2009) 6:42. doi:10. 1186/1743-0003-6-42

253. Zhou IY, Liang YX, Chan RW, Gao PP, Cheng JS, Hu Y, et al. Brain restingstate functional MRI connectivity: morphological foundation and plasticity. Neuroimage (2014) 84:1-10. doi:10.1016/j.neuroimage.2013.08.037

254. Tenney JR, Duong TQ, King JA, Ludwig R, Ferris CF. Corticothalamic modulation during absence seizures in rats: a functional MRI assessment. Epilepsia (2003) 44:1133-40. doi:10.1046/j.1528-1157.2003.61002.x

255. Chahboune H, Mishra AM, Desalvo MN, Staib LH, Purcaro M, Scheinost D, et al. DTI abnormalities in anterior corpus callosum of rats with spikewave epilepsy. Neuroimage (2009) 47:459-66. doi:10.1016/j.neuroimage.2009. 04.060
256. Nersesyan H, Herman P, Erdogan E, Hyder F, Blumenfeld H. Relative changes in cerebral blood flow and neuronal activity in local microdomains during generalized seizures. J Cereb Blood Flow Metab (2004) 24:1057-68. doi:10.1097/ 01.WCB.0000131669.02027.3E

257. Nersesyan H, Hyder F, Rothman DL, Blumenfeld H. Dynamic fMRI and EEG recordings during spike-wave seizures and generalized tonic-clonic seizures in WAG/Rij rats. J Cereb Blood Flow Metab (2004) 24:589-99. doi:10.1097/01. WCB.0000117688.98763.23

258. Desalvo MN, Schridde U, Mishra AM, Motelow JE, Purcaro MJ, Danielson $\mathrm{N}$, et al. Focal BOLD fMRI changes in bicuculline-induced tonic-clonic seizures in the rat. Neuroimage (2010) 50:902-9. doi:10.1016/j.neuroimage. 2010.01.006

259. Polack PO, Mahon S, Chavez M, Charpier S. Inactivation of the somatosensory cortex prevents paroxysmal oscillations in cortical and related thalamic neurons in a genetic model of absence epilepsy. Cereb Cortex (2009) 19:2078-91. doi:10.1093/cercor/bhn237

260. Straessle A, Loup F, Arabadzisz D, Ohning GV, Fritschy JM. Rapid and longterm alterations of hippocampal GABAB receptors in a mouse model of temporal lobe epilepsy. Eur J Neurosci (2003) 18:2213-26. doi:10.1046/j.1460-9568. 2003.02964.x

261. Timofeev I, Bazhenov M, Avramescu S, Nita DA. Posttraumatic epilepsy: the roles of synaptic plasticity. Neuroscientist (2010) 16:19-27. doi:10.1177/ 1073858409333545

262. Pitkanen A, Kemppainen S, Ndode-Ekane XE, Huusko N, Huttunen JK, Grohn O, et al. Posttraumatic epilepsy - disease or comorbidity? Epilepsy Behav (2014). doi:10.1016/j.yebeh.2014.01.013

263. Zhang Q, Wu ZC, Yu JT, Zhong XL, Xing YY, Tian Y, et al. Anticonvulsant effect of unilateral anterior thalamic high frequency electrical stimulation on amygdala-kindled seizures in rat. Brain Res Bull (2012) 87:221-6. doi:10.1016/j.brainresbull.2011.11.023

264. Langlois M, Polack PO, Bernard H, David O, Charpier S, Depaulis A et al. Involvement of the thalamic parafascicular nucleus in mesial temporal lobe epilepsy. J Neurosci (2010) 30:16523-35. doi:10.1523/JNEUROSCI.110910.2010

265. Arabadzisz D, Antal K, Parpan F, Emri Z, Fritschy JM. Epileptogenesis and chronic seizures in a mouse model of temporal lobe epilepsy are associated with distinct EEG patterns and selective neurochemical alterations in the contralateral hippocampus. Exp Neurol (2005) 194:76-90. doi:10.1016/j. expneurol.2005.01.029

266. Marx M, Haas CA, Haussler U. Differential vulnerability of interneurons in the epileptic hippocampus. Front Cell Neurosci (2013) 7:167. doi:10.3389/fncel. 2013.00167

267. Khalilov I, Holmes GL, Ben-Ari Y. In vitro formation of a secondary epileptogenic mirror focus by interhippocampal propagation of seizures. Nat Neurosci (2003) 6:1079-85. doi:10.1038/nn1125

268. Morrell F. Experimental focal epilepsy in animals. Arch Neurol (1959) 1:141-7. doi:10.1001/archneur.1959.03840020015003

269. Ben-Ari Y, Lagowska J, Tremblay E, La Salle G. A new model of focal status epilepticus: intra-amygdaloid application of kainic acid elicits repetitive secondarily generalized convulsive seizures. Brain Res (1979) 163:176-9. doi:10.1016/0006-8993(79)90163-X

270. Sobayo T, Mogul DJ. Rapid onset of a kainate-induced mirror focus in rat hippocampus is mediated by contralateral AMPA receptors. Epilepsy Res (2013) 106:35-46. doi:10.1016/j.eplepsyres.2013.03.010

271. Sabatino M, Gravante G, Ferraro G, Vella N, La Grutta G, La Grutta V. Striatonigral suppression of focal hippocampal epilepsy. Neurosci Lett (1989) 98:285-90. doi:10.1016/0304-3940(89)90415-1

272. Rektor I, Kuba R, Brazdil M, Chrastina J. Do the basal ganglia inhibit seizure activity in temporal lobe epilepsy? Epilepsy Behav (2012) 25:56-9. doi:10.1016/j.yebeh.2012.04.125

273. Krook-Magnuson E, Armstrong C, Oijala M, Soltesz I. On-demand optogenetic control of spontaneous seizures in temporal lobe epilepsy. Nat Commun (2013) 4:1376. doi:10.1038/ncomms2376

274. Paz JT, Davidson TJ, Frechette ES, Delord B, Parada I, Peng K, et al. Closed-loop optogenetic control of thalamus as a tool for interrupting seizures after cortical injury. Nat Neurosci (2013) 16:64-70. doi:10.1038/nn.3269

275. Mirski MA, Rossell LA, Terry JB, Fisher RS. Anticonvulsant effect of anterior thalamic high frequency electrical stimulation in the rat. Epilepsy Res (1997) 28:89-100. doi:10.1016/S0920-1211(97)00034-X 
276. Hamani C, Ewerton FI, Bonilha SM, Ballester G, Mello LE, Lozano AM. Bilateral anterior thalamic nucleus lesions and high-frequency stimulation are protective against pilocarpine-induced seizures and status epilepticus. Neurosurgery (2004) 54:191-5. doi:10.1227/01.NEU.0000097552.31763.AE

277. Takebayashi S, Hashizume K, Tanaka T, Hodozuka A. The effect of electrical stimulation and lesioning of the anterior thalamic nucleus on kainic acid-induced focal cortical seizure status in rats. Epilepsia (2007) 48:348-58. doi:10.1111/j.1528-1167.2006.00948.x

278. Lado FA. Chronic bilateral stimulation of the anterior thalamus of kainatetreated rats increases seizure frequency. Epilepsia (2006) 47:27-32. doi:10.1111/ j.1528-1167.2006.00366.x

279. Fisher R, Salanova V, Witt T, Worth R, Henry T, Gross R, et al. Electrical stimulation of the anterior nucleus of thalamus for treatment of refractory epilepsy. Epilepsia (2010) 51:899-908. doi:10.1111/j.1528-1167.2010.02536.x

280. Jackson JH. Lectures on the diagnosis of epilepsy. Br Med J (1879) 1:33-6. doi:10.1136/bmj.1.941.33

281. Jackson JH. Lectures on the diagnosis of epilepsy. Br Med J (1879) 1:141-3. doi:10.1136/bmj.1.944.141

282. Jackson JH. Lectures on the diagnosis of epilepsy. Br Med J (1879) 1:109-12. doi:10.1136/bmj.1.943.109
283. Sander JW. Comorbidity and premature mortality in epilepsy. Lancet (2013) 382:1618-9. doi:10.1016/S0140-6736(13)61136-8

Conflict of Interest Statement: The authors declare that the research was conducted in the absence of any commercial or financial relationships that could be construed as a potential conflict of interest.

Received: 18 July 2014; accepted: 08 October 2014; published online: 05 November 2014.

Citation: Pittau F, Mégevand P, Sheybani L, Abela E, Grouiller F, Spinelli L, Michel CM, Seeck M and Vulliemoz S (2014) Mapping epileptic activity: sources or networks for the clinicians? Front. Neurol. 5:218. doi: 10.3389/fneur.2014.00218

This article was submitted to Epilepsy, a section of the journal Frontiers in Neurology. Copyright (C) 2014 Pittau, Mégevand, Sheybani, Abela, Grouiller, Spinelli, Michel, Seeck and Vulliemoz. This is an open-access article distributed under the terms of the Creative Commons Attribution License (CC BY). The use, distribution or reproduction in other forums is permitted, provided the original author(s) or licensor are credited and that the original publication in this journal is cited, in accordance with accepted academic practice. No use, distribution or reproduction is permitted which does not comply with these terms. 